\title{
Dokumentation
}

\section{Die Volkszählung auf dem Rechtsweg}

\author{
I. Michael Breitbach/Ulli F. H. Rühl \\ Das Zensurverbot im Grundgesetz - eine \\ verdrängte Freiheitsgarantie ${ }^{*}$
}

\section{Problemstellung}

Die nachfolgend abgedruckten Beschlüsse, samt und sonders in Eilverfahren nach $\$ 80$ Abs. 5 oder $\ 1_{23}$ Abs. I VwGO ergangen, sind Teil der Auseinandersetzungen in der Öffentlichkeit um die Durchführung der Volkszählung 1987. Sie betreffen behördliche Verbote, Informationsstände durch Kritiker der Volkszählung aufste]len zu dürfen. Während die nordrhein-westfälischen Gerichte die Entscheidungen als eine Frage der straßenrechtlichen Genehmigung aufzäumen, hat die hessische Rechtsprechung diesen Weg mit der Begründung ausgeschlossen, die Straßenbehörden hätten sich für ihre Entscheidungen auf wegerechtliche Aspekte zu beschränken, ${ }^{1}$ und statt dessen das Polizeirecht bemüht. Während die straßenrechtliche Konstruktion den Konflikt als Streit um einen Anspruch auf eine Genehmigung abbildet, erweisen sich die Maßnahmen der Ordnungsbehörden als Streitigkeiten um Verbotseingriffe.

Unabhängig von diesen dogmatischen Einkleidungen geht es im Kern um die Frage, inwieweit im Bereich öffentlicher Kommunikation Gefahrenabwehr rechtlich zulässig ist. Dies ist zunächst einmal die Frage nach Reichweite und Umfang des grundgesetzlichen Zensurverbotes gem. Art. s Abs. i Satz 3 GG. Soweit die Verbote bzw. verweigerten Genehmigungen gegenüber den beantragten Informationsständen sich auf die Weiterverbreitung von bereits existierenden Büchern und periodischen Schriften beziehen, wird zwar der sonstige Vertrieb, etwa über Buchhandlungen, nicht gestoppt; rechtlich bleibt aber dennoch zu fragen, ob diese Art behördlicher Verbote gegenüber der Weiterverbreitung solcher Schriften mit der Exklusivität des Presserechts in Widerspruch steht.

Alle diese Fragen werden praktisch durch die Gerichte verdrängt. Dies legt die Vermutung nahe, daß ein Bedarf für Zensurmaßnahmen offenbar für unumgänglich

\footnotetext{
* Anmerkungen zu den Beschlüssen des VG Darmstadt III/2 H 7II $/ 87$, Beschl. v. 23. 4. 87; III/V H $754 / 87$ Beschl. v. 24. 4.87; III/V H $825 / 87$, Beschl. v. 7. 5.87; des VG Düsseldorf 16 L $833 / 87$, Beschl. v. 21 . 5. 87 ; des OVG Münster 23 B 1037/87, Beschl. v.r4.5.87 und 23 B 1167/87, Beschl. v. 22.5.87. Abgedruckt unten S. $213 \mathrm{ff}$

I VGH Kassel NVwZ 1987, 902 ff. unter Aufgabe seiner früheren Rspr; mit dieser Entscheıdung war ein Beschluß der Zweiten Kammer des VG Darmstadt v. 3.4.1987- Az.: II/3 G 600/87 - bestätıgt worden, worauf dann die Behörden die in den zit. Beschlüssen des VG Darmstadt Ende April und Ma1 1987 genannten Verbote erlassen hatten.
} 
gehalten wird. Gerade weil es sich um Eilverfahren handelt, bei denen wegen des summarischen Charakters sicher nicht jedes Argument unbedingt auf die juristische Goldwaage gelegt werden sollte, erscheint diese plausibel: Denn Eilentscheidungen erfordern den schnellen Zugriff auf das rechtlich Selbstverständliche und lassen deshalb oft repräsentative Bewußtseinslagen deutlicher hervortreten. So wird aber auch erkennbar, was eben verdrängt ist. ${ }^{2}$

Das im Zensurverbot verankerte absolute Verbot der Gefahrenabwehr im Kommunikationsbereich, Ergebnis des langen Kampfes um die Herausbildung einer Sphäre politischer Öffentlichkeit, spielt auch in der Kommentarliteratur kaum mehr eine Rolle. ${ }^{3}$ Eine bemerkenswerte Ausnahme bildet lediglich die Kommentierung von C. Starck in der dritten Auflage des v. Mangoldt/Klein: "Springender Punkt des Verbots von Vorzensur ist gerade, daß durch sie nicht präventiv verhindert werden darf, was später vor Gericht verfolgt werden darf. « ${ }^{4}$ Diese Fassung des Zensurverbotes stellt einen expliziten Bezug zur Geschichte des Zensurverbotes im 19. Jahrhundert her. Dies sei hier nur am Beispiel eines Beitrages von Fr. v. Gentz dokumentiert, der sich als Berater Metternichs für die Beibehaltung des Zensursystems aussprach: »Die Freiheit der Gedankenmittheilung kann bekanntlich auf zwei verschiedenen Wegen vor Mißbrauch bewahrt werden. Entweder durch Anordnungen, die diesem Mißbrauch vorzubeugen bestimmt sind, oder durch solche, die ihn nach der That zum Gegenstande gesetzlicher Ahndung machen. Die ersten gehören in die Klasse der Polizergesetze, und werden im gegenwärtigen Falle Censuranstalten genannt. Die anderen müssen Strafgesetze sein .... Angelpunkt des Gentz'schen Plädoyers für die Beibehaltung der Zensur ist nun dessen Funktion zu verhindern, daß schädliche Publikationen überhaupt Öffentlichkeitswirkungen entfalten können: nur so sei dem "Mißbrauch der Presse ... auf die unschädlichste und zweckmäßigste Weise « zu wehren; denn die nachträgliche Sanktion komme hierfür einfach zu spät. ${ }^{6}$

\section{Das Zensurverbot und die Schranke der allgemeinen Gesetze}

Die Ursache der skizzierten Entfremdung der Fachjuristen vom Zensurverbot kann im Rahmen dieses Beitrages nur angedeutet werden. Sie mag einerseits mit dem inflationären Gebrauch des Wortes Zensur im politischen Alltag zusammenhängen; als Kampfbegriff gebraucht, verblaßt seine juristische Prägnanz. Andererseits und fachwissenschaftlich wohl primär dürfte der Dissens über Gegenstand und Reichweite des Zensurverbotes damit zusammenhängen, daß es verfassungsgesetzlich über den Bereich der Presse hinaus auf alle Kommunikationsmedien ausgedehnt wurde

2 Vgl. dazu auch unseren Betrag in NJW 1988, 8 (13); das gilt auch für das OVG Koblenz NJW 1987, 2250 , das en Versammlungsverbot für Volkszählungsgegner gem. \Is VersammlG bestätıgte.

3 Vgl. dazu Brettbach/Rühl NJW 1988,8 (10 ff.).

4 V. Mangoldt/Klein/Starck, GG I, 3. Aufl. 1985 , Art.s I, II Rdnr. 103. Damit knüpft Starck an eine Äußerung von Häntzschel aus der Weımarer Zeit an, wonach nur solche Maßnahmen nicht unter das Zensurverbot fallen, »die nach Begehen einer strafbaren Handlung oder nach Eintritt eınes polizeswidrsgen Zustandes geschehen, um die weitere Verbreıtung « zu verhındern, ın: Anschütz/Thoma, HdbDtStR II, 1932, S. 651 .

5 Friedrich v. Gentz, Die Pressefreiheit in England, in: Pressefreihett, hrsgg. v. J. Wilke, Darmstadt 1984, S. I 42 ff. ( 144 f.); Hervorhebung im Onginal. Auch in der Debatte um die Paulskirchenverfassung wurde das Zensurverbot jedenfalls als spezifisches Mittelverbot hınsıchtlich von Präventıvmaßregeln gefordert und begriffen; vgl. nur. H. Scholler, Die Grundrechtsdiskussion in der Paulskurche, Darmstadt 1973, S. 19 .

6 F. v. Gentz, Anm. s, S. 1 47. - Der Versuch von v. Gentz, die Voraussetzungen und Folgen des Systems der Zensur denjenıgen des Systems bloß nachträglicher Sanktıonen gegenüberzustellen, ist trotz aller Parteilichkeiten dieses Fürstenberaters auch heute noch teilwerse von beachtlichem Erkenntnıswert. 
und so im Verhältnis zur pressebezogenen Fachdebatte im 19. Jahrhundert ganz neuartige Konkretisierungsaufgaben erzwang, wie unschwer Beispiele aus dem Versammlungswesen oder gar hinsichtlich des gesprochenen Wortes belegen. Ferner dürften die interpretatorischen Versuche zur Ausdehnung des Zensurbegriffs, die Entwicklung eines materiellen - im Gegensatz zu einem »bloß « formellen Zensurbegriffs mit dem Ziel, auch die sog. Nachzensur dem verfassungsrechtlichen Verbot zu unterwerfen, dafür verantwortlich sein, daß das Zensurverbot im Strudel der Wechselwirkungslehre verschwunden ist.?

Diese auf den ersten Blick vielleicht paradox klingende Feststellung läßt sich damit erklären, daß ein formelles Verbot der Vorzensur mit der Möglichkeit der nachträglichen Sanktion von Kommunikationsunrecht ja widerspruchsfrei vor Art. s Abs. 2 GG zu rechtfertigen ist. Die Beschränkungen der Meinungs- oder auch Pressefreiheit im Sinne des Art. s Abs. 2 GG lassen sich eben nachher zur Geltung bringen; denn das Zensurverbot verbietet nur die polizeiliche Gefahrenabwehr, also die Prävention im Kommunikationssektor. Aus diesem Grunde ist es auch dogmatisch unproblematisch, die Schranken des Art. s Abs. 2 GG nucht auf das Zensurverbot anzuwenden. Probleme entstehen erst, wenn man auch die Nachzensur in Art. $S$ Abs. 1 S. 3 GG einbezieht. Denn die Folge davon ist, daß eine Meinungs- oder Presseäußerung von der rechtlichen Folgenverantwortung freigestellt wird. Eine generelle Freistellung von solcher Verantwortung für Äußerungen ist aber wegen der grundgesetzlichen Schranken nicht durchzuhalten. So wird erforderlich, die rechtmäßige von der rechtswidrigen Sanktion für den Gebrauch der Meinungsfreiheit zu unterscheiden. Von da aus haben aber die verschiedensten Interessen dogmatisch leichtes Spiel, sich gegenüber dem Zensurverbot doch noch Geltung zu verschaffen, indem sie mit der Nachzensur auch die Vorzensur den Schranken des Art. s Abs. 2 GG unterwerfen.

Genau diesen Weg geht das VG Düsseldorf. Zum Verlangen der Stadt Wesel gegenüber dem Antragsteller, die auf seinem Stand beabsichtigten Informationen offenzulegen, erklärt das VG: „Es ist davon auszugehen, daß grundsätzlich eine Vorzensur bei politischen Informationsveranstaltungen nicht stattfindet. Eine andere Beurteilung ist dann möglich, wenn konkrete Anhaltspunkte dafür sprechen, daß bei einer derartigen Veranstaltung zu strafbaren Handlungen oder Ordnungswidrigkeiten aufgerufen wird. ${ }^{8}$ Dem Gericht entgeht damit die entscheidende Funktion des Zensurverbotes, mit den Mitteln polizeilicher Gefahrenabwehr gerade nicht das Verbotene aufspüren und präventiv verhindern zu dürfen. Denn dies war ja auch, was immer wieder verkannt wird, das Interesse der Metternich'schen Zensurbehörden, unerlaubte Äußerungen der Öffentlichkeit und dem Publikum vorzuenthalten: Der verbotene Gedanke sollte ohne jede Chance sein, überhaupt etwas bewirken zu können.

Die formelle Natur des Zensurverbotes erweist sich gerade darin, daß sie den Zugang von Meinungsäußerungen zum Publikum »ohne Rücksicht darauf, ob sie materiell einen erlaubten oder nicht erlaubten Inhalt haben «, rechtlich offenhält und vor präventiven Eingriffen schützt. ${ }^{9}$ Die Fixierung auf das Kriterium »unerlaubte Handlung«, welches für das Zensurverbot völlig unerheblich ist, verstellt hier folgenreich den Blick: Das VG Düsseldorf scheint eine Vorlagepflicht mit seiner

7 Exemplarısch für die Ausdehnungsbemühungen etwa M. Löffler AfP 1969, 886 ff.; kritısch etwa H. Ridder AfP $1969,882 \mathrm{ff}$.

8 VG Düsseldorf unten S. 2 I6. Ebenso schon BayVGH BayVBl 1983, s5: "Zwar dürfen die Behörden auf den Inhalt einer Kundgebung nucht mit Auflagen enwirken, da dies enner von Art.s Abs. I S. 3 verbotenen Zensur gleıchkäme ... Dies gilt jedoch nur für rechtlich nıcht allgemeın verbotene Themen.* 9 Formulierung von K. Häntzschel, Anm. 4, S. 667. 
Begründung für rechtlich möglich zu halten. Nur im konkreten Fall sieht es keine genügenden tatsächlichen Anhaltspunkte dafür, daß der Antragsteller sich zu verbotenen Äußerungen und Informationen hinreißen lassen werde. Das Verbot einer Vorlagepflicht zum Zwecke der Genehmigung oder Unbedenklichkeitsbescheinigung rechnet aber zum klassischen Gehalt des Zensurverbotes. ${ }^{10}$

Das straßenrechtliche Genehmigungsverfahren für die Aufstellung von Informationsständen gebietet nicht, die dort auszulegenden Schriften vorher vorzulegen auch nicht verkleidet als eine Mitwirkungspflicht des Bürgers im Rahmen eines Verwaltungsverfahrens, welche die Stadt Wesel trickreich zu begründen sucht. Dies folgt nicht nur aus rein immanent straßenrechtlichen Gründen, worauf alleine die hessische Rechtsprechung ihre Argumentation ausrichtet. Eine Vorlagepflicht ist auch durch das Zensurverbot mit seinem Verdikt gegenüber der Uraltmethode von Vorlagepflicht und Genehmigung ausgeschlossen.

\section{Zensurverbot und Abwägung}

Die Klippe eines Vorlage- und Genehmigungsverfahrens, dessen Zensurcharakter mit Händen zu greifen ist, umschifft das OVG Münster in der Begründung seiner Beschwerdeentscheidung zu VG Düsseldorf, weil es den Konflikt als einen solchen widerstreitender Interessen aufbaut, der zur Abwägung zwinge: In diese Abwägung wird sodann einerseits das Interesse (!) an der Wahrnehmung des Rechts (!) auf freie Meinungsäußerung eingestellt, andererseits "das Recht der Allgemeinheit, die Straßen innerhalb des näher konkretisierten Gemeingebrauchs ... jederzeit nach Belieben benutzen zu können." Eine Abwägung zugunsten des Antragstellers hält das OVG nur dann für möglich, »wenn sein Vorhaben dem Schutz des Art. s unterliegt ${ }^{\prime \prime}{ }^{11}$

Das OVG übergeht nun geflissentlich das in Art. 5 Abs. x S. 3 GG enthaltene Zensurverbot und hält die ausschließliche Einschlägigkeit bloß der Garantie der Meinungsfreiheit für derart evident, daß es statt dessen einfach fortfährt: »Das Recht auf freie Meinungsäußerung und -verbreitung ist nicht uneingeschränkt gewährleistet, sondern findet seine Schranken insbesondere in den Vorschriften der allgemeinen Gesetze (Art. s Abs. 2 GG). Demgemäß würde es an einem beachtlichen Gewicht des Interesses des Antragstellers fehlen, wenn aufgrund der Gesamtumstände, die bei der Entscheidung über die Erteilung der Erlaubnis zu berücksichtigen sind, von vornherein erkennbar ist, die Grenzen freier Meinungsäußerung und -verbreitung würden bei der Erteilung der Erlaubnis aller Voraussicht nach überschritten werden. ${ }^{12}$ Der Antragsteller wird vom OVG nun vom Verdacht der Verbreitung unerlaubter Äußerungen und von der Pflicht, das zur Verbreitung bestimmte Publikationsmaterial vorzulegen, freigestellt. Freilich nur deshalb, weil "maßgeblich ... der Vortrag des Antragstellers (ist), am Informationsstand würden keine Materialien verteilt werden, die zum Boykott der Volkszählung aufforderten ... Dies hat der Prozeßbevollmächtigte des Antragstellers bei seiner - fernmündlichen - Anhörung zur Beschwerde des Antragsgegners ausdrücklich bekräftigt. «" 3

10 So immerhın auch V. Götz, Allgemeınes Polizeı- und Ordnungsrecht, 8. Aufl. 1985, Rdnr. I69; vgl ferner BVerfGE 33, 52, $72 \mathrm{ff}$.

11 OVG Münster unten S.218. Die Interessenabwägung bildet auch 1m Beschluß v. 14.5.1987 das dogmatısche Herzstück.

I 2 OVG Münster unten S. 218.

I3 OVG Münster unten S. 218. Darın liegt eıne Parallele zum Fall des VG Köln NJW 1971, 2 Iof,, das dem Veranstalter einer Demonstratıon ene vergleıchbare Loyalitätserklärung abverlangte und abnahm; es handelte sıch damals um eine Veranstaltung aus dem Umfeld der Aktion Widerstand. 
Statt der Vorlage des Materials wird entscheidungserheblich die Loyalitäts- und Unterwerfungserklärung, bestimmte Äußerungen nicht zu tun. Noch selbst diese Reinigung vom Verdacht kann versagen, nämlich »wenn konkrete Erkenntnisse dafür vorliegen, daß solche Aufforderungen gerade dieser Gruppierung zuzuordnen sind, und wenn aus ihnen mit hinreichender Wahrscheinlichkeit abgeleitet werden kann, bei der beantragten Veranstaltung werde zum Boykott aufgefordert werden «. ${ }^{14}$ Von der Antwort darauf, ob jemand einem bestimmten politischen Umfeld zuzuordnen ist, von dem vermutet werden kann, was er äußern wird, hängt also ab, ob ein Verbot zulässig sein soll. Nur im Zusammenhang mit der Weigerung, Informationsmaterial im Verwaltungsverfahren zur Prüfung vorzulegen, geht das OVG auf das zur Auslage bestimmte Informationsmaterial ein und meint, daraus "läßt sich noch nicht von vornherein erkennen, die Grenze freier Meinungsäußerung werde ... überschritten «. ${ }^{\text {Is }}$

Über die Konstruktion der Zuordnung von Personen zu kritischen Gruppen oder Protestpotential in der Gesellschaft wird so ein noch viel weitergreifendes Zensurmittel geboren: Zielte die Vorlage von Material darauf, gewisse, identifizierbare und nicht bloß prognostizierte Äußerungen zu bewerten, so reicht nach dem OVG der Verdacht aus. "Träger" von unerlaubten Meinungen könnten nach dieser Logik präventiv, übrigens auch unterhalb der Schwelle von Art. 18 GG, zum Schweigen gebracht werden.

Methodisch interessant ist dabei, daß die staatliche Prävention über einen rechtlichen Abwägungsvorgang inszeniert wird, um »das Recht der Allgemeinheit, die Straßen ... jederzeit nach Belieben nutzen zu können «, zu schützen. Diese, ein völlig fiktives Freiheitlichkeitspathos beschwörende Abwägungsperspektive des OVG - exemplarisch für die ganz überwiegende Rechtsprechung - ist es, die das von der Vorinstanz immerhin noch wahrgenommene Zensurverbot aus dem Blick verschwinden läßt. Die Dethematisierung endet damit, die verweigerte Vorlage hier wenigstens nicht als Indiz für geplante unerlaubte Äußerungen zu werten - zumal sich ein Organ der Rechtspflege für deren Ungefährlichkeit verbürgt hatte: Aus dem Zensurverbot wird eine Frage der Gefahrenprognose!

Das Abwägungsverfahren erlaubt schließlich, obrigkeitlichen Zensurpraktiken den Mantel der Freiheitsgewährung umzuhängen. Genau darin dürfte die besondere Beliebtheit der Abwägungs'methode < bei den Rechtsanwendungsorganen liegen, gestattet sie ihnen doch, die privilegierte Interessenwahrnehmung der in den Staatsapparaten versammelten Eliten als Gewährleistung von Freiheit, allerdings bloß ihrer eigenen, darzustellen.

\section{Zensurverbot und konkrete Gefabrenabwebr}

Ein weiterer Grund, warum in der Rechtspraxis die Bedeutung des Zensurverbotes verkannt wird, dürfte in der selten ganz klar ausformulierten Vorstellung wurzeln, Zensur sei »abstrakte" Gefahrenabwehr; konkrete Gefahrenabwehr gegenüber Kommunikationsunrecht im Einzelfall habe dagegen mit Zensur nichts mehr zu tun. ${ }^{16}$ Dieser Überscheidung wird - indirekt - in der Literatur Nahrung gegeben, wenn zur Abgrenzung von verbotener Nachzensur und erlaubter Sanktion von

14 OVG Münster unten S. 218

Is OVG Münster unten S. 218.

16 So etwa V. Götz, Anm. 10, Rdnr. 169, der Gefahrenabwehr nicht generell, sondern nur das »besonders ... enschneidende Gefahrenabwehrverfahren, nämlich das Verbot mıt Erlaubnisverfahren « als verboten begreift; in diese Richtung auch schon Anschütz, WRV, 14. Aufl., Berlin 1933, Art. 18 Anm. 7. 
Kommunikationsunrecht maßgeblich auf das Kriterium der Planmäßigkett von Überwachung als zensurbegründendem Kriterium zurückgegriffen wird. ${ }^{17}$

Nun ist der Erlaß einer Verbotsnorm, die bestimmte Äußerungen als Kommunikationsunrecht inkriminiert, ja abstrakte Gefahrenabwehr - und dennoch nicht verfassungsrechtlich ausgeschlossen. Nicht darauf zielt das Zensurverbot, es geht vielmehr darum, daß - wie C. Starck formuliert - nicht unterdrückt werden darf, was später noch geahndet werden kann. Mit anderen Worten: das Zensurverbot dekretiert ein "Abtreibungsverbot « gegenüber Kommunikationsakten. ${ }^{18}$ Mit dem in der Literatur vorgeschlagenen Kriterium der Planmäßigkeit der Überwachung wird aber tendenziell eine Rechtlosstellung des von einer Zensurmaßnahme Betroffenen organisiert: Dieser hätte die Planmäßigkeit von Überwachung über seinen Einzelfall hinaus nachzuweisen. Angesichts der neuen Überwachungstechnologien ein schwieriges Unterfangen, da diese anders als noch die klassische Pressezensur mit ihrer Vorlagepflicht ja immer weniger auf die Mithilfe der Betroffenen angewiesen ist, von diesen also gar nicht bemerkt werden muß. Damit ist die Planmäßigkeit ohne weiteres hinter den nur punktuell sichtbar werdenden Zugriffen zu kaschieren. Allenfalls vom »Glücksfall« massenhafter und gleichzeitiger Verbote könnte der Rückschluß auf planmäßiges Überwachen erfolgen. Ironischerweise wird die systematische Überwachung von der Rechtsprechung insofern vorausgesetzt, als die Behörden ihre Gefahrenprognose, es werde zu einem Akt von Kommunikationsunrecht kommen, auf Tatsachen stützen müssen: Verlangt wird so die Sammlung einschlägigen Materials! ${ }^{19}$

Die These, konkrete Gefahrenabwehr im Kommunikationsbereich werde vom Zensurverbot nicht erfaßt, raubt dem Zensurverbot heute jede praktische Bedeutung. Sie macht die verfassungsgesetzliche Ausdehnung des Zensurverbots auf alle Kommunikationsrechte des Art. s GG weitgehend gegenstandslos: Das live gesprochene Wort ist ja nie »vorlagefähig «. Mit dieser Konstruktion lassen sich wie gezeigt "Träger « bestimmter Meinungen präventiv bekämpfen, was letztlich immer nur mit gezielter, planmäßiger Überwachung vor allem einschlägiger Szenen möglich ist. Woher sollte man sonst die "Trägerschaft « kennen? Mit dieser juristischen Finte wären zwar die alten konstitutionellen Grobschlächtigkeiten überwunden, die jedermann zur Vorlage seiner Schriften gezwungen und damit spürbarer Überwachung preisgegeben hatte. Die daraus resultierenden politischen Kosten, die eben auch von der eigenen Klientel zu entrichten waren, werden nunmehr vermieden. Die neuartige ökonomisierte und verfeinerte Zensurpraxis trifft so nur die gesellschaftlichen Gruppen, die ohnehin von Ausgrenzung und Diskriminierung bedroht sind. So schwindet das Bedürfnis, auch diese wie alle generell und in gleicher Weise vor Zensur zu bewahren. Darauf ist zurückzuführen, daß ein partielles themenspezifisches Öffentlichkeitsverbot verhängt werden kann, was jüngere Vorgänge wie der Streit um die Volkszählung und die Konferenz der Partei der GRÜNEN im Januar 1987 in Nürnberg belegen. ${ }^{20}$

Wohin es führen kann, wenn sich staatliche Gerichte eine Zensurkompetenz aneignen, dafür bildet die Kette der Darmstädter Beschlüsse der dritten Kammer des

17 So neben Löffler, PresseR I, 2. Aufl., 1969, 6. Kapitel Rdnr. 4 etwa auch Hoffmann-Riem, AK-GG, 1984 , Art. S Abs. I, 2 Rdnr. 76.

I 8 H. Ridder AfP 1969, 882 (883): "Die Bemessung der >Publikatıonsphaser ist schwierı. Mit eınem vielleicht gewagten und ungenau bleibenden Bild: Das ZV verbietet Antikonzeption, Abtreibung und Kindestötung von Werken für den Meinungsprozeß.« Vgl. dort auch den Befund über den "ın der Rechtsprechung zu beobachtenden Trend, dem ZV möglichst aus dem Wege zu gehen " (882).

I9 Vgl. OVG Münster unten S. 218, 219; ferner BayVGH NJW 1981, $2428 \mathrm{ff}$.

20 Vgl. dazu Brettbach/Rühl NJW 1988, 8 m. w. N.; ferner auch den Fall des BayVGH BayVBl 1983, $54 \mathrm{f}$. sowse die Anmerkung des ein weitergehendes Kritikverbot fordernden Richters Czermak. 
VG ein denkwürdiges Beispiel: So ist, was noch am 23.4.87 verboten war, am 7. 9.87 erlaubt. Was war geschehen? Die GRÜNEN hatten im Bundestag zwischenzeitlich einen Gesetzesentwurf eingebracht, der die Aufhebung des Volkszählungsgesetzes 1987 vorsah. Dadurch, so das VG, konnte »die Volkszählung insoweit auch Gegenstand der freien Meinungsäußerung bleiben bzw. werden «. Es ist das »bzw.«, das Unsicherheit indiziert: Hätte die Volkszählung ohne die Befassung des Bundestages mit dem - aussichtslosen - Aufhebungsgesetz nicht Gegenstand der Meinungsfreiheit »bleiben bzw. werden « können? Wodurch wäre die Volkszählung ohne den Aufhebungsantrag der Diskussion durch das Volk entzogen worden? Konnte sie nur deshalb wieder zum Diskussionsgegenstand werden, weil der Bundestag das Thema wieder aufnahm? Kurz: das VG geht von der Vorstellung aus, mit der Entscheidung des Gesetzgebers sei das Thema vom Tisch, öffentlicher Diskussion entzogen und also kein Gegenstand von Meinungsfreiheit mehr. Es zeichnet ein sicher extrem zugespitztes Modell öffentlicher Willensbildung als (parteien-)staatlich gesteuerten Prozesses, in dem die Staatsorgane dem Volk vorgeben, was Gegenstand der Meinungsfreiheit sein und werden kann. Ein solches Bild einer an die Eliten gebundenen Öffentlichkeit kommt vielleicht dem Selbstverständnis einer konstitutionellen Monarchie, aber keineswegs dem Öffentlichkeitsgebot des demokratischen Verfassungsstaates nahe.

\section{Die Polizeifestigkeit der Pressefreiheit}

Über den Zensuraspekt hinaus sind die Beschlüsse des VG Darmstadt und des OVG Münster vom 14. 5. 1987 auch presserechtlich unhaltbar. Sie ignorieren die Exklusivität des Presserechts für pressebezogene Maßnahmen, worin sich rechtlich der Grundsatz der Polizeifestigkeit der Pressefreiheit manifestiert. Sie ziehen wahlweise Straßenrecht, so das OVG Münster, oder polizeirechtliche, so das VG Darmstadt, oder auch sonstige Ermächtigungsnormen wie z. B. $\$$ is Versammlungsgesetz ${ }^{2 t}$ als Rechtsgrundlagen heran, was im Hinblick auf die rechtsstaatliche Kultur in diesem unseren Lande schon einigermaßen beunruhigend ist. Sicher hat dies aber auch mit der Spezifik der Sachverhalte und der in ihnen verankerten Interessenstrukturen zu tun, die den Blick auf die Presseproblematik verstellen. Bei Informationsständen oder Versammlungen steht im Vordergrund des Interesses die Äußerung eines Veranstalters. Zur Stützung seiner Äußerungen nutzt er nur vorhandenes Schrifttum. Das hat die Rechtspraxis für den Bereich des Versammlungswesens auch veranlaßt, die Verbreitung von Schrifttum bei Versammlungen als versammlungstypisch zu betrachten mit der Folge, daß gewerberechtliche Vorschriften durch das Versammlungsgesetz verdrängt werden. ${ }^{22}$ So plausibel es ist, den Gewerbecharakter politischer Veranstaltungen insoweit rechtlich auszuschließen, so falsch wäre es, die zum besonderen Schutz der Presse ergangenen Regelungen unter Rückgriff auf das sonstige Polizei- und Ordnungsrecht zu unterlaufen. Daß auch hierfür jedes Gespür bei den Gerichten abhanden gekommen zu sein scheint, wird womöglich noch durch den Umstand begünstigt, daß die Verbote "nur" eine punktuelle Verbreitungsform betreffen, die für den Autor und Urheber ohnehin nur zufällig zustande kommt; die üblichen und normalen Vertriebswege über den Buchhandel, an deren Funktionieren ihm in erster Linie gelegen sein dürfte, werden dadurch nicht

2I Vgl. hierzu den Fall des OVG Koblenz NJW 1987, 2250, wo diese Folge wegen der bei Versammlungen inzwischen häufig anzutreffenden Verbreıtung von Publikatıonen, die den Versammlungszweck stützen, mitbetroffen sein könnte.

22 So etwa VG München NJW 1983, 1219 ; zustımmend die Literatur, vgl. nur Dietel/Gintzel, Demonstrations- und Versammlungsfreiheit, 8. Aufl. 1985, \$Is Rdnr. 17. 
verstopft. Die aktionsbezogene Zensurtechnik läßt oberflächlich nur den Veransta]ter als betroffen erscheinen, den ja auch primär der Bannstrahl des Schweigens treffen soll. Dessen auch pressebezogene Verbreitungstätigkeit gerät so offenbar, aber eben zu Unrecht aus dem Blick.

Für die Maßnahmen gegenüber den unter das Presserecht fallenden Produkten gelten nun aber ganz besondere Anforderungen. Zunächst schließen ausnahmslos alle Pressegesetze der Länder die Anwendung anderer als verfassungsunmittelbarer Beschränkungen der Pressefreiheit neben den Pressegesetzen selbst aus. Es gehört zudem zum festen Bestand des Polizei- und Ordnungsrechts, daß Druckwerke nicht der Sicherstellung aufgrund polizeirechtlicher Bestimmungen unterliegen. ${ }^{23}$ Die Pressefreiheit ist das klassische Beispiel für die Polizeifestigkeit der Grundrechte. Die Exklusivität presserechtlicher Normen zur Beschränkung der Pressefreiheit wird lediglich durchbrochen durch bundesgesetzliche Normen der Strafprozeßordnung, die in den $\mathbb{S}$ IIIm, I I In in Verbindung mit $\mathbb{\$}$ I r r StPO die Sicherstellung zur Vorbereitung der Einziehung ( $\$ 74 \mathrm{~d}$ StGB) und in $\$ 94$ StPO die Sicherstellung der Beweissicherung regeln. ${ }^{24}$ Das geltende Presserecht schafft einen Formenzwang, dem die öffentliche Gewalt unterworfen ist.

Das gegenüber den Volkszählungsboykott-Initiativen praktizierte partielle Verbreitungsverbot kommt unter diesen Formen nicht vor. Ein Wiederabdruck- und Verbreitungsverbot - sehr plastisch auch als "Verhaftung des Gedankens« bezeichnet - setzt eine wirksame Pressebeschlagnahme voraus. Das hessische Pressegesetz läßt die Beschlagnahme überhaupt nur bei bestimmten Straftaten zu. $\$$ I3 HessPresseG enthält hierzu einen enumerativen Katalog; Aufforderungsdelikte, wie sie gegenüber den genannten Initiativen geltend gemacht werden, ${ }^{25}$ sind in diesem Katalog nicht enthalten. Die übrigen Landespressegesetze verweisen auf $\$ 74 \mathrm{~d}$ $\mathrm{StGB}$, so z. B. $₫ 1_{3}$ Abs. 2 des baden-württembergischen und des nordrheinwestfälischen PresseG, und lassen die Beschlagnahme zu, wenn die Verbreitung des Druckwerkes den Tatbestand eines Strafgesetzes nach dem StGB verwirklicht. Das Verbreitungsverbot gilt nach allen Landespressegesetzen nur für die Dauer der Beschlagnahme, so daß generell - auch im Falle der vorläufigen Sicherstellung durch die Staatsanwaltschaft nach $\$ ig NWPresseG, $\$ i 8 BWPresseG - gilt: kein Verbreitungsverbot ohne Beschlagnahme.

\title{
II. Das verdrängte Zensurverbot: Rechtsprechung zum Volkszählungsboykott
}

\author{
I. VG Darmstadt, Beschluß vom 23.4.1987-III/2 $\mathrm{H}_{7 I I / 87}$ \\ [Verbot eines VoBo-Informationsstandes]
}

Mit Verfügung vom 10. 4. 1987 wurde dem Antragsteller die Aufstellung eines Informationsstandes in Neu-Isenburg, Bahnhofstraße/Ludwigstraße/Luisenstraße an den im Tenor genannten Daten untersagt sowie das Verbreiten von Schriften, Ton- oder Bildträgern, Abbildungen oder Darstellungen noch durch Ansprechen von Passanten im Rahmen von Informa-

23 V. Götz, Anm. 10, Rdnr. 169; Rolf Groß, Presserecht, 2. Aufl. 1987, S. 212 m.w. N.

24 Zur Frage der Gesetzgebungskompetenz des Bundes für presserechtliche Beschlagnahmeregelungen, vgl. R. Groß, Anm. 23, S. $204 \mathrm{ff}$.

25 Vgl. hrerzu die Begründungen bei VG Darmstadt unten S. 214,215 und OVG Münster unten S. 218,219 sow1e VG Düsseldorf unten S. $216 \mathrm{f}$; inwiewcit Aufforderungsdelikte mit dem Kriterium des allgeme1nen Gesetzes in Einklang stehen, muß her freilich offenbleiben. 
tionsständen zum Boykott der Volkszählung aufzufordern. Es wurde die sofortige Volkziehbarkeit der Verfügung angeordnet. [...]

Der Bürgermeister als Ortspolizeibehörde der Stadt Neu-Isenburg war berechtigt, polizeirechtlich begründete Verbotsverfügungen zu erlassen, da er dafür zumindest in Anbetracht der Dringlichkeıt der Angelegenheit eine Eilzuständigkeit in Anspruch nehmen kann.

Die Verfügung ist auch hinsichtlich des Verbotes, zum Boykott der Volkszählung aufzufordern, rechtmäßig. [...] Eine Aufforderung zum Boykott eines so verfassungsrechtlich ordnungsmäßig zustande gekommenen Gesetzes braucht von einer Polizeibehörde nicht hingenommen zu werden. Es gibt kein verbrieftes Recht, verfassungsmäßig zustandegekommene Gesetze zu boykottieren. Die Einhaltung von verfassungsmäßig zustande gekommenen Gesetzen gehört zu den Bürgerpflichten eines jeden Bürgers der Bundesrepublik Deutschland. Es ist nicht Sache des Antragstellers, darüber zu befinden, ob ein Gesetz verfassungsgemäß zustande gekommen ist oder nicht oder ob es gar über verfassungswidrıgen Inhalt verfügt. Dazu befugt ist allein das Bundesverfassungsgericht.

Es ist daher polizeirechtlich nicht zu beanstanden, wenn ein Verbot zur Aufforderung zum Boykott ausgesprochen wird.

Der Antragsteller hat auch durch sein bisheriges Verhalten Anlaß gegeben, ein derartiges Verbot von Seiten der Polizeibehörde auszusprechen. Es wurde dem Gericht ein Flugblatt »Volkszählungsboykott-warum? « vorgelegt, für das die Gruppe, für die der Antragsteller auftritt, die "Erfassungsschutzgruppe", zumindest mitverantwortlich zeichnet. In diesem Flugblatt wird eindeutig und unmißverständlich zum Boykott der Volkszählung aufgefordert. Dieses Flugblatt stellt kein Informationsflugblatt dar, sondern eine Handlungsanweisung, wie man einen Volkszählungsboykott durchführen kann und was man dabei zu beachten hat, also eine Handlungsanweisung für diesen Boykott. Dies jedoch ist eine klare Aufforderung zur Nichtbeachtung des Volkszählungsgesetzes. Eine solche Handlungsanweisung zum Boykott einschließlich einer Rechtsberatung hierzu bzw. eines Angebotes zu einer Rechtsberatung erfüllt den Begriff des Aufforderns.

[...]

Ein Aufruf zum Boykott des Volkszählungsgesetzes ist folglich nicht nur verboten, sondern kann auch von der Polizeibehörde durchgesetzt werden.

Nicht durchsetzen kann die Polizeibehörde jedoch ein Informationsverbot über die Volkszählung. Der Antragsteller hat einen Anspruch darauf, im Rahmen des Art. 8 Grundgesetz darüber zu informieren, worüber er informieren will. Er darf dabei auch enne Meinung äußern, auch in deutlicher und klarer Weise. Nicht vom Art. 8 umfaßt ist lediglich der Aufruf zum Boykott eines verfassungsmäßigen Gesetzes. Meinungsfreiheit geht nämlich nur soweit, soweit sie nicht mit anderen Gesetzen kollidiert. ... Ein völliges polizeirechtlich begründetes Verbor jeglicher Informationsstände an allen genannten Tagen ıst unverhältnısmäßig, da die Information ohne gesetzeswidrigen Inhalt nicht verboten werden kann. [...]

Im übrigen ist zu erwähnen, daß die Frage, welche einzelnen Schriften nun inhaltlich zum Boykott des Volkszählungsgesetzes auffordern, eme Sache der Vollstreckung der insoweit für rechtmäßig gehaltenen Verfügung darstellt. Es sei auch in diesem Zusammenhang betont, daß sowohl die sachliche Information als auch die klare Meinungsäußerung von Art. $8 \mathrm{GG}$ umfaßt wird, und daß lediglich der Aufruf zum Boykott eines verfassungsmäßigen Gesetzes verboten werden darf.

Bei der gegenseitigen Interessenabwägung ist zu Gunsten des Informationsstandes aufgrund von Art. 8 GG und in Anbetracht der Tatsache, daß diese Eilentscheidung nahezu eine Vorwegnahme der Hauptsache darstellt, davon auszugehen, daß das Interesse an der Verwirklichung eines Grundrechtes Vorrang vor dem Schutzinteresse, jegliche Meinungsäußerung zum Volkszäh]ungsgesetz zu verbieten, hat. [...]

\section{VG Darmstadt v. 24.4.1987-III/V $\mathrm{H}_{754 / 87}$ \\ [Verbot der Verbreitung von VoBo-Literatur]}

$[\ldots]$

Die Anordnung gegen einen Volkszählungboykott ist grundsätzlich rechtmäßig, denn der Antragsteller begründet durch sein Verhalten und Vorhaben die Gefahr, das öffentliche Interesse zu beeinträchtigen, indem er durch Wort und Schrift zum Volkszählungsboykott auffordern will, was eine Ordnungswidrigkeit gegen die öffentliche Sicherheit bzw. auch eine Verletzung der öffentlichen Ordnung darstellt.

Dıe Volkszählung ıst gültıger Bestandteil des öffentlichen Interesses, denn das Volkszählungsgesetz ist ein nach den Rechtsprechungsmaßstäben des Bundesverfassungsgerichts zustande 
gekommenes Gesetz, und über seine Verfassungsmäßigkeit hat allenfalls und allein das Bundesverfassungsgericht zu entscheiden, nucht der Antragsteller im Rahmen seiner beabsichtigten Boykottaufforderung. Das Vorhaben des Antragstellers ist nämlich mehr als nur eine ebenfalls verfassungsmäßige "kritische" Meinungsäußerung über die Volkszählung, es ist vielmehr eine Boykottaufforderung:

Eine solche Aufforderung besteht nach der z. B. auch im Strafrecht gültigen Begriffsbestimmung in einer an andere gerichteten Äußerung, die andere zu einer Rechts- bzw. Ordnungswidrigkeit bestimmen oder auch nur in einem bereits gefaßten Entschluß bestärken soll. Es genügt dabei eine Aufforderung auch durch schlüssiges Verhalten, sogar auch in der Erteilung eines Rates.

Eine derart kennzeichnende Aufforderung ist insbesondere bei entsprechender Sinnfälligkeit der Äußerung zu bejahen, etwa bei unmittelbar zielgerichtetem Gebrauch des Wortes »Boykott «, wohl nicht unbedingt bereits beim Einsatz umfangreicherer Druckerzeugnisse, denen eine solche für den Aufforderungsadressaten überschaubare Unmittelbarkeit fehlen mag, es sei denn, daß er im einzelnen darauf aufmerksam gemacht wird, sei es durch Aufblättern, Unterstreichung, Worthinweis oder sonstwie. [...]

Nach diesen Maßstäben ist das Vorhaben des Antragstellers zum größten Teil rechts- und ordnungswidrig.

$[\ldots]$

Zwar hätte die Antragsgegnerin wohl auch das Gesamtvorhaben, das der Antragsteller als bloße »Information « ausgibt, untersagen können, denn das Vorhaben erhält seine maßgebliche Gesamtprägung auswerslich der genannten Belege nicht durch eine rechtmäßige »kritische" Information, sondern vorrangig durch sein rechtswidriges Ziel eines Volkszählungsboykotts, wobei der Antragsteller als $Z$ weckveranlasser auftritt, der mit legalen Mitteln einen insgesamt illegalen Zweck verfolgt. [...]

Aber die Antragsgegnerin hat gleichwohl ihre Untersagung auf die von ihr bezeichneten Einzeltatbestände einer Aufforderung beschränkt, was derart dann auch für das Gericht die maßgebliche Vorgabe ist. [...]

Beı diesen Einzeltatbeständen erweist sich die Schrift Rottmann/Strohm: Was Sie gegen ... die Volkszählung tun können, im ganzen Zusammenhang der S. 167 bis 174 als rechtswidrige Aufforderung zum "Boykott der Volkszählung 1987« mit der weiteren Aufforderung »sich auf jeden Fall einer Boykott-Gruppe anschließen « zu »sollen«.

$[\ldots]$

Dagegen enthalten lediglich die Schrift Appel/Hummel: Vorsicht Volkszählung! sowie Kubicek/Rolf: Mikropolis soweit ersichtlich keine derart sınn- und unmittelbar auffälligen Aufforderungen zu einem Volkszählungsboykott. [...]

Die Anordnung hat den Antragsteller indessen nicht nur gegenständlich mit dem größten Teil solcher Druckerzeugnisse oder sonstiger "Schrift« als ordnungsrechtlichen Handlungsstörer auf Unterlassung in Anspruch genommen, sondern auch persönlich, indem sie ihm eine Aufforderung auch durch »Wort« ebenfalls zu Recht untersagt hat, wozu sie sowert ersichtlich aus vorangegangenem Verhalten des Antragstellers Anlaß hat und was der Antragsteller in seiner Antragsschrift auch selber nicht aufgreift oder gar in Abrede stellt. [...]

\section{VG Darmstadt v. 7.5. $1987-I I I / V H ~ 825 / 87$ \\ [Verbot von VoBo-Informationsständen]}

$[\ldots]$

Für die rechtlichen Maßstäbe, nach denen die sofortige Vollziehbarkeit einer Anordnung gegen einen Volkszählungsboykott ausgesetzt werden kann, verbleibt es grundsätzlich bei dem Beschluß III/N H 754/87.

Dies gilt auch für die Möglichkeit, ein Gesamtvorhaben, das ein Antragsteller als bloße Information und freie Meinungsäußerung ausgibt, zu untersagen, wenn dieses seine maßgebliche Gesamtprägung nicht durch eine rechtmäßige kritische Meinungsäußerung erhält, sondern vorrangig durch das rechtswidrige Ziel eines Volkszählungsboykotts, wobei ein Antragsteller als Zweckveranlasser mit legalen Mitteln einer Meinungsäußerung den insgesamt illegalen Zweck des Boykotts eines geltenden Gesetzes verfolgt. [...]

Bei der Anwendung insbesondere dieses letzteren Maßstabes auf den vorliegenden Fall kann das Gericht aufgrund einer seit dem Beschluß III/V H 754/87 veränderten Sach- und Recbtslage nicht von einer offensichtlichen Rechtmäßigkeit der Gesamtuntersagung für den Informationsstand des Antragstellers ausgehen.

Zwar hat die Antragsgegnerin den Informationsstand des Antragstellers insgesamt untersagt, 
weil sie aus den näher dargelegten Gründen dessen vorrangige Gesamtprägung gegen das öffentliche Interesse gerichtet sah, insbesondere als ordnungswidrigen Boykottaufruf gegen das Volkszählungsgesetz als Schutzgegenstand der öffentlichen Sicherheit, aber wohl auch als Gegenstand der bloßen öffentlichen Ordnung. Und noch im Verfahren III/V H $754 / 87$ hätte die Antragsgegnerin mit einer gerichtlichen Bestätigung dafür rechnen können, dem Antragsteller seinen Informatıonsstand insgesamt als rechtswidrige Gefährdung der Volkszählung zuzurechnen.

Aber eine solche Sach- und Rechtslage besteht inzwischen nicht mehr mit solcher Deutlichkeit, ein rechtmäßiger Informationszweck wird nicht mehr insgesamt durch einen rechtswidrigen Boykottzweck überlagert, sondern beide Zwecke stehen soweit ersichtlich (wieder) selbständig rechtlich wertungsfähig nebeneınander: Es ist nämlich inzwischen ein Gesetzentwurf bzw. eine dahingehende Absicht bekannt geworden, das Volkszäblungsgesetz 1987 aufzuheben.

Ein solcher Gesetzentwurf bzw. eine solche Absicht mag zwar keine oder nur eine geringe Erfolgsaussicht haben. A ber gleichwohl ist dadurch nicht nur das kritische Für und Wider über ęne Volkszäblung, sondern auch wenn nicht nur Gültigkeit, so doch die Geltung des Volkszählungsgesetzes über eine bloße außerparlamentarische Boykottierung hinaus rechtmäBig auf die Ebene des Gesetzgebungsverfabrens gestellt worden.

Bei solcher Entwicklung der Sach- und Rechtslage kann die Volkszählung insoweit auch Gegenstand der freien Meinungsäußerung bleiben bzw. werden, und nur das darüber hinauszielende selbständige Vorgehen gegen die gleıchwohl erforderliche Befolgung des bestehenden Volkszählungsgesetzes ist eine untersagungsfähige Gefahr für das öffentliche Interesse.

Hiernach verbleibt es für die Anordnung der Antragsgegnerın sowıe für die Entscheidung des Gerichts bei den bestimmten einzelnen Boykotthandlungen des Antragstellers und deren sofort vollziehbare Untersagung. [...]

Ob darüber hinaus der Informationsstand des Antragstellers wegen Mißbrauchs legaler Mittel der Information und Meinungsäußerung für einen illegalen Aufruf gegen die Beachtung des Volkszählungsgesetzes doch noch znsgesamt untersagt werden kann, ist im Zeitpunkt der gerichtlichen Entscheidung nicht voraussehbar und bleibt etwaiger Überprüfung durch die Antragsgegnerin vorbehalten. [...]

\section{VG Düsseldorf v. $21.5 \cdot 1987-16 L 833 / 87$ \\ [Antrag auf Erteilung einer Sondernutzungserlaubnis für VoBo- Informationsstand]}

$[\ldots]$

Der Antrag auf Erlaß einer einstweiligen Anordnung mit dem Ziele,

dem Antragsgegner aufzugeben, dem Antragsteller die beantragte Sondernutzungserlaubnis für die Durchführung eines Informationsstandes am Samstag, den 23. Mai 1987 in der Zeit von I0.00 Uhr bis $14.00 \mathrm{Uhr}$ in der Fußgängerzone der Innenstadt in Wesel zu erteilen, hat Erfolg.

$[\ldots]$

Der Antragsteller hat einen Anspruch auf die begehrte Entscheidung. Nach $₫$ I 8 StrWG NW bedarf die Benutzung der Straße über den Gemeingebrauch hinaus als Sondernutzung der Erlaubnis der Straßenbaubehörde. Die Gemeinde kann durch Satzung die Ausübung der Sondernutzung regeln $(\$ 19$ StrWG). Das ist in der Sondernutzungssatzung der Stadt Wesel vom 20. Dezember $x 985$ geschehen. Nach $\$ 2$ der Sondernutzungssatzung ist die Errichtung des Informationsstandes im öffentlichen Straßenraum der Stadt Wesel genehmigungspflichtig. Nach dem vorliegenden Sachverhalt sprechen insbesondere nach dem Inhalt des ablehnenden Bescheides des Antragsgegners vom 6. Mai 1987 und seiner Stellungnahme in diesem Verfahren vom 21. Mai 1987 keine Gründe für eine ermessensgerechte Verweigerung des beantragten Informationsstandes, so daß im Hinblick auf die in Art. s GG garantierte Meinungsfreiheit (BVerfGE 20, 56 ff. $-98-$ ) dem Antragsteller aus den vom Antragsgegner angeführten Gründen der Informationsstand nicht verweigert werden darf. [...]

Soweit sich der Antragsgegner bei seiner ablehnenden Entscheidung vom 6. Mai 1987 darauf stützt, der Antragsteller habe durch seine Weigerung, die auf seinem Stand beabsichtigten Informationen offenzulegen, seine Mitwirkungspflicht verletzt, folgt die Kammer dieser Auffassung nicht. Es ist davon auszugehen, daß grundsätzlich eine Vorzensur bei politischen Informationsveranstaltungen nıcht stattfindet. Eine andere Beurteilung ist dann möglich, wenn konkrete Anhaltspunkte dafür sprechen, daß beı einer derartigen Veranstaltung zu strafbaren Handlungen oder Ordnungswidrigkeiten aufgerufen wird. Das wäre dann der Fall, wenn zu 
einer Verletzung der in $\$$ I 2 des Volkszählungsgesetzes 1987 (BGBl. I S. 2078 ff.) normierten Auskunftspflicht aufgerufen würde. Denn das wäre nach $\$ 23$ Abs. I des Bundesstatistikgesetzes vom 22. Januar 1987 (BGBl. I S. 462 ff.) i. V.m. $\ 116$ OWiG eine mit Bußgeld bedrohte Handlung, zu deren Unterstützung durch Erteilung ener straßenrechtlichen Erlaubnis der Antragsgegner nicht verpflichtet wäre.

Es ist dem Antragsgegner zuzugestehen, daß anläßlich der Diskussion über die Volkszählung zahlreiche derartige Boykottaufrufe gegenüber der Volkszählung ergangen sind. Das ist dem erkennenden Gericht aus anderen Verfahren hinlänglich bekannt. Es gibt andererseits aber auch rechtlich zulässige politische Stellungnahmen, die das Volkszählungsgesetz zwar politisch angreifen, nicht aber zum Gesetzesbruch aufrufen oder ihn bestärken. Derartige Auseinandersetzungen sind im politischen Meinungskampf erlaubt und dürfen nicht Gegenstand einer Vorzensur sein. Zur Freiheit der politischen Auseinandersetzung in einer Demokratie gehört es, auch Kritik an bestehenden Gesetzen zu ertragen und es hinzunehmen, wenn konkurrierende politische Auffassungen um eine Mehrheit mit dem Ziel werben, bestehende Gesetze zu ändern. In diesem Zusammenhang wird auch der Hinweis an den Bürger noch zulässig sein, das bestehende Gesetz genau anzuwenden und sich gegen eine erweiternde oder gar mißbräuchliche Anwendung mit rechtlichen Schritten zu wehren. Erst wenn zum Boykott des Gesetzes und der danach dem Bürger obliegenden Pflichten aufgerufen wird, wäre die Grenze des zulässigen politischen Meinungskampfes überschritten. Daß die »Volkszählungsinitiative Wesel «, deren Mitglied der Antragsteller ist, dem Volkszählungsgesetz kritisch gegenübersteht, ist anzunehmen. Daß die Volkszählungsinitiative dagegen strafbare Handlungen oder Ordnungswidrigkeiten begehen wird, kann nicht von vornherein unterstellt werden mit der Folge, die auf einem Informationsstand auszulegenden Schriften einer Vorzensur unterziehen zu wollen. Auch wenn anderenorts derartige Vorfälle nicht mehr selten sind und dadurch die politische Auseinandersetzung im Zusammenhang mit der Volkszählung häufig die Grenzen demokratisch erlaubten Meinungsstreites verlassen hat, darf mangels hinreichender Anhaltspunkte im konkreten Falle nicht ohne weiteres gefolgert werden, auch die Volkszählungsinitiative Wesel werde in gleicher Weise gegen das Gesetz verstoßen. Darum ist die Aufforderung an den Antragsteller, seine Informationsschriften zwecks Überprüfung offenzulegen, nicht angemessen. Die Verweigerung hat darum nicht eine Mitwirkungspflicht verletzt. [...]

\section{OVG Münsterv.22.5. 1987-23 $B_{1167 / 87}$ [Zurïckweisung der Beschwerde gegen Beschluß des VG Düsseldorf, s.o. 4.]}

Die zulässige Beschwerde ist nicht begründet.

[...]

Der Antragsteller bedarf für die Abhaltung eines Informationsstandes der beantragten Art als einer den Gemeingebrauch ( $\$$ I4 Abs. I Satz I StrWG NW) überschreitenden Benutzung öffentlicher Straßen einer Erlaubnis des Antragsgegners als Straßenbaubehörde ( $\$$ × 8 Abs. I Satz 2, 56 Abs. 2 c StrWG NW), deren Erteilung im Ermessen des Antragsgegners steht. $[\ldots]$

Um den gebotenen Interessenausgleich ermessensgerecht vornehmen zu können, ist eine Abwägung der gegenseitigen Belange geboten, deren Ergebnis ausschlaggebend von den jeweiligen Umständen des Einzelfalls und hierbei insbesondere von dem $\mathrm{Ma} ß$ der Beeinträchtigung der gegenläufigen Rechte und Interessen abhängt. (Vgl.: BVerwG, Beschl. v. 7. April $1987-7$ B 182.86 -, Amtl. Umdruck S. 4.) In die Abwägung einzustellen ist einerseits das Interesse des Sondernutzers an der Durchführung seines Vorhabens mit dem diesem Interesse objektiv beizumessenden Gewicht. Als solches Interesse kommt hier das Recht des Antragstellers auf freie Meinungsäußerung und -verbreitung im Rahmen der nicht unwesentliche Teile der Öffentlichkeit beschäftigenden Diskussion über die Durchführung des Volkszählungsgesetzes 1987 in Betracht.

Demgegenüber sind zu Lasten des Antragstellers die Belange von Bedeutung, deren Schutz der Fürsorge der für die Ordnung der Benutzung der Straßen zuständigen Straßenbaubehörden anvertraut ist. Der Sondernutzung gegenläufig sind in erster Linie verkehrliche Gesichtspunkte; denn bei der Ermessensentscheidung der Straßenbaubehörden geht es vornehmlich darum, Gefahren für die Sicherheit und Leichtigkeit des Verkehrs auszuschließen oder doch in erheblichem Maße zu mindern. (Vgl.: BVerwG, Urt. v. 7. Juni 1978, E 56, 63/S. 67.)

[...] Das Recht der Allgemeinheit, die Straßen innerhalb des näher konkretisierten Gemeingebrauchs [...] jederzeit nach Belieben benutzen zu können, das in seinem Kerngehalt der grundrechtlichen Gewährleistung der Art. 2 Abs. I, 3 Abs. 1 und 14 Abs. 1 GG unterliegt, 
(vgl.: BVerwG, Urt. v. 25. September I968 - IV C 195.65 -, BVerwGE 30, 235 (238)) ist in jedem Fall zu beachten und bei der gebotenen Abwägung der gegenseitigen Belange den für die Sondernutzung angeführten Interessen gegenüberzustellen. Demgemäß kommt eine Ermessenschrumpfung auf Null und damit ein Anspruch auf die Erlaubnis auch bei Fehlen der Gefahr konkreter Verkehrsbehinderungen oder Störungen des Straßenumfelds nur dann in Betracht, wenn das Interesse des Sondernutzers so gewichtig ist, daß es gegenüber dem stets zu beachtenden Recht der Allgemeinheit auf uneingeschränkten Gemeingebrauch überwiegt. (Im Ergebnis a. A.: Hess. VGH Beschl. v. 3. April 1987-2 TG 911/87-, unter Aufgabe der früheren Rechtsprechung (NJW I983, 2280 ff.))

Das Interesse des Antragstellers an einer Meinungsäußerung zur Volkszählung 1987, insbesondere an der Aufstellung eines entsprechenden Informationsstandes, könnte hier nur dann überwiegen, wenn sein Vorhaben dem Schutz des Art. S GG unterliegt. [...] Demgemäß würde es an einem beachtlichen Gewicht des Interesses des Antragstellers fehlen, wenn auf Grund der Gesamtumstände, die bei der Entscheidung über die Erteilung der Erlaubnis zu berücksichtigen sind, von vornherein erkennbar ist, die Grenzen freier Meinungsäußerung und -yerbreitung würden bei Erteilung der Erlaubnis aller Voraussicht nach überschritten werden. Letzteres wäre etwa dann der Fall, wenn öffentlich oder durch Verbreiten von Schriften zu einem sanktionierten Verstoß gegen die nach dem Volkszählungsgesetz 1987 bestehende Auskunftspflicht aufgefordert wird. [...]

Ausgehend von diesen für die Ermessensentscheidung des Antragsgegners maßgeblichen Grundsätzen hat der Senat - was bei einem gerichtlichen Eilverfahren der hier vorliegenden Art nur möglich und geboten ist - summarisch geprüft, ob und inwieweit das ihm vorliegende Tatsachenmaterial und der Vortrag der Beteiligten die Annahme besorgen lassen, bei Aufstellung des fraglichen Informationsstandes würde im Zusammenhang damit zum Boykott bzw. zu einem Unterlaufen der Volkszählung aufgefordert werden. Da aufgrund dieser Prüfung keine Anhaltspunkte vorliegen, die es hinreichend wahrscheinlich sein lassen, bei Erteilung der begehrten Erlaubnis würde zu einem sanktıonierten Verstoß gegen die bestehende Auskunftspflicht aufgefordert werden, war ferner zu prüfen, ob dem beantragten Informationsstand jedenfalls so gewichtige verkehrliche Belange entgegenstehen, die enen Eingriff in die freie Meinungsäußerung und -verbreitung rechtfertigen. Auch diese Frage war zu verneinen. Im einzelnen gilt folgendes:

Maßgeblich ist der Vortrag des Antragstellers, am Informationsstand würden keine Materialien verteilt werden, die zum Boykott der Volkszählung aufforderten; am Informationsstand werde ein Boykottaufruf nicht stattfinden. Dies hat der Prozeßbevollmächtigte des Antragstellers bei seiner - fernmündlichen - Anhörung zur Beschwerde des Antragsgegners ausdrücklich bekräftigt.

Hinreichende Anhaltspunkte, diesem Vortrag des Antragstellers nicht zu folgen, liegen nicht vor. $\mathrm{Da}$ der Antragsteller es im Verwaltungsverfahren abgelehnt hatte, zur Verteilung vorgesehenes Informationsmaterial dem Antragsgegner zur Prüfung vorzulegen, läßt noch nicht von vornherein erkennen, die Grenze freier Meinungsäußerung werde bei einer Abhaltung des begehrten Informationsstandes durch ihn bzw. durch die Initiative, für die er handelt, überschritten. Z $Z$ war ist dem Senat aus verschiedenen, dem vorliegenden Verfahren vergleichbaren Gerichtsverfahren sowie aufgrund der Berichterstattung der Medien bekannt, daß Aufforderungen, die Volkszählung zu boykottieren, in unterschiedlicher Form von verschiedenen Gruppierungen erfolgt sind, namentlich auch durch Verteilen von entsprechenden Flugblättern. Diese Tatsache rechtfertigt jedoch nur dann einen Schluß auf das Verhalten des Antragstellers und der »Volkszählungsinitiative Wesel«, wenn konkrete Erkenntnisse dafür vorliegen, daß solche Aufforderungen gerade dieser Gruppierung zuzuordnen sind, wenn aus ihnen mit hinreichender Wahrscheinlichkeit abgeleitet werden kann, bei der beantragten Veranstaltung werde zum Boykott der Volkszählung aufgefordert werden. Erkenntnisse dieser Art liegen dem Senat jedoch nicht vor.

Sie ergeben sich insbesondere nicht aus dem Flugblatt "Volkszählung ' 87 Zehn Minuten, die allen schaden «... Zwar wird in diesem Flugblatt eindeutig zum Boykott und zu einem Unterlaufen der Volkszählung aufgefordert. Für das Flugblatt ist jedoch offensichtlich mit einem Pseudonym presserechtlich verantwortlich gezeichnet und es enthält auch unter Berücksichtigung des bei den Verwaltungsvorgängen des Antragsgegners befindlichen polizeilichen Ermittlungsberichts vom I4. Mai 1987 keine Angaben, aus denen der Senat ohne weiteres mit hinreichender Deutlichkeit eine Zuordnung dieses Flugblatts zu der Initiative des Antragstellers ableiten kann. [...] 
Der Antragsteller begehrt für die "Initiative für aktiven Datenschutz« im Wege der einstweiligen Anordnung die Verpflichtung des Antragsgegners zur Erteilung einer Sondernutzungserlaubnis für einen wiederholt aufzustellenden Informationsstand zur Volkszählung 1987. Dem Antragsteller waren vom Antragsgegner zunächst für zwei Samstage (11. und 18. April 1987) entsprechende Erlaubnisse erteilt worden, wobei die Erlaubnisbescheide jeweils u.a. die "Auflage« enthielten, es dürfe nıcht zum Boykott der Volkszählung aufgerufen werden. Insbesondere dürfe das gelbe Flugblatt "Volkszählung 1987" nicht verteilt werden. Mit Bescheid vom 23. April 1987 versagte der Antragsgegner die Erlaubnis für weitere beantragte Termine im wesentlichen mit der Begründung, der Antragsteller habe bei den genehmigten Veranstaltungen durch Verteilen von Flugblättern am Informationsstand zum Boykott der Volkszählung aufgerufen, so daß davon auszugehen sei, dies werde auch in Zukunft geschehen; für solche Empfehlungen könne das Recht auf freie Meinungsäußerung nicht in Anspruch genommen werden. Der Antragsteller hat gegen diesen Bescheid Widerspruch erhoben. Mit Beschluß vom 29. April 1987 hat das Verwaltungsgericht den Antragsgegner im Wege der einstweiligen Anordnung verpflichtet, dem Antragsteller die Sondernutzungserlaubnis zum Aufstellen eines Informationsstandes an mehreren Samstagen zu erteilen. Hiergegen richtet sich die Beschwerde des Antragsgegners.

Die zulässige Beschwerde ist begründet.

$[\ldots]$

In dem vom Antragsgegner vorgelegten gelben Flugblatt „Volkszählung 1987«, für das der Antragsteller presserechtlich verantwortlich gezeichnet hat, wird eindeutig zum Boykott und zu einem Unterlaufen der Volkszählung aufgefordert. Denn in dem Flugblatt ist u. a. ausgeführt: „Die Volkszählung als Instrument staatlicher Kontrolle muß undurchführbar gemacht werden. Für immer. Das kann nur heißen: Vollständiger, offener Boykott ... Wir rufen dazu auf, das Zählen zu boykottieren ...« Nach bei den Verwaltungsvorgängen des Antragsgegners befindlichen Vermerken eines Polizeibeamten bzw. städtischer Kontrolleure hat der Antragsteller dieses Flugblatt, dessen Verteilen in den Erlaubnisbescheiden für die Informationsstände vom 11. und I8. April 1987 vom Antragsgegner ausdrücklich als Boykottaufruf gewertet worden war, am II. und 18. April 1987 verteilt, und zwar am letztgenannten Termin direkt vom genehmigten Informationsstand aus. Demgegenüber hat der Antragsteller in seiner im Gerichtsverfahren vorgelegten eidesstattlichen Versicherung vom 24. April 1987 in Kenntnis des Vorwurfs, durch die Verteilung der Flugblätter am Informationsstand zum Boykott der Volkszählung aufgerufen zu haben, lediglich erklärt, das Flugblatt "Volkszählung 1987" habe sich nicht auf dem Informationsstand befunden. Für die rechtliche Beurteilung der vom Antragsteller beantragten Aufstellung eines Informationsstandes ist jedoch nicht allein der Inhalt der ausgelegten Druckschriften bedeutsam. Sinn und Zweck eines Informationsstandes der hier in Rede stehenden Art ist es gerade, vom Stand aus die Straßenpassanten anzusprechen und ihnen Materıal an die Hand zu geben. Demgemäß ist das dabei gezeigte Gesamrverhalten der den Informationsstand betreibenden Personen zu berücksichtigen und zu werten. Angesichts dessen läßt das Gesamtvorbringen des Antragstellers bei verständiger Würdigung erkennen, er halte sich auch weiterhin für berechtigt, bei einer Abhaltung des begehrten Informationsstandes im Zusammenhang damit das erwähnte Flugblatt - oder anderes vergleichbares gedrucktes Material - zu verteilen. Damit ist hinreichend wahrscheinlich, der Antragsteller werde sich auch dementsprechend verhalten und somit bei der beantragten Veranstaltung zum Boykott der Volkszählung auffordern.

Hiernach ist nicht glaubhaft gemacht, daß das Interesse des Antragstellers als so gewichtig anzusehen wäre, daß es gegenüber dem Recht der Allgemeinheit auf uneingeschränkten Gemeingebrauch überwiegt, und daß ihm ein seinen Antrag rechtfertigender Anordnungsanspruch zusteht. [...] 


\title{
III. »Zählsorge«-Urteil des Staatsgerichtshofs für das Land Baden-Württemberg vom 28. I. 1988
}

\author{
[Zurückweisung des Antrags auf Feststellung, daß die Sperrung des Informationste- \\ lefons der Landtagsfraktion "DIE GRÜNEN" gegen die Landesverfassung $(B W)$ \\ verstößt]
}

\section{Entscheidungsgründe: \\ $[\ldots]$}

Der Präsident des Landtags hatte gemäß der ihm nach Art. 32 Abs. 2 LV zustehenden Polizeigewalt im Sitzungsgebäude des Landtags aufgrund des gegebenen Sachverhalts die Befugnis, am I 2. 3. I 987 den Fernsprechanschluß 2063-472 des Abgeordneten Dr. Schwandner zu sperren, der unter seiner Beteiligung von der Fraktion der "Grünen « zur Unterstützung von Boykottaktionen gegen die Volkszählung ... verwendet werden sollte (sog. "ZählsorgeTelefon $\ll) .[\ldots]$

Aus dem gesamten Zusammenhang der von den Antragstellern selbst vorgelegten beiden Flugschriften vom Februar 1987 geht eindeutig hervor, daß sich die Fraktion der »Grünen « in Verbindung mit dem Landesverband dieser Partei an boykottuerenden Maßnahmen durch Information und Beratung sowohl von Bürgern als auch von Zählern über das "ZählsorgeTelefon« beteiligen wollte. Entsprechende Auskünfte wurden offenbar bereits erteilt oder standen zumindest unmittelbar bevor. Die Urheber der Aktion cinschließlich der Antragsteller waren sich der Rechtswidrigkeit bewußt, gegen die Durchführung eines ordnungsgemäß erlassenen, geltenden Gesetzes aufzurufen. Sie bezeichneten ihre Aktion in dem allgemeinen Flugblatt selbst dahingehend, daß mit zivilem Ungehorsam zur Nichtbefolgung eines Gesetzes aufgerufen werde. [...]

2. In diesem Verhalten der Antragsteller lag eine schwerwiegende konkrete Bedrohung der Rechtsordnung in Gestalt einer Verletzung der verfassungsmäßigen Ordnung, die nach $\mathbb{S}$ I PolG in besonderem Maße Schutzgut der Polizeigewalt ist. Die Abgeordneten und Fraktionen des Landtags verfügen einerseits wegen ihrer parlamentarischen Aufgaben über besondere Rechte, insbesondere über den Status des sogenannten freien Mandats im Sinne von Art. 27 Abs. 3 LV. Andererseits sind die Parlamentarier nicht von der Beachtung der Verfassungs- und Rechtsordnung ausgenommen. Dem Landtag mit seinen Abgeordneten und Fraktionen ist nach Art. 27 Abs. 2 LV die gesetzgebende Gewalt und damit im Zusammenhang die Überwachung der Ausübung der vollziehenden Gewalt anvertraut. Zur ordnungsgemäßen Wahrnehmung dieser grundlegenden Staatsfunktionen obliegt den Abgeordneten und Fraktionen in ganz besonderem Maße die Pflicht, sich an die elementaren Verfassungsgrundsätze zu halten. Hierzu gehört nach Art. 23, 25 LV das Rechtsstaats- und Demokratieprinzip. Beiden Prinzipien mißt die Landesverfassung nach Art. ${ }_{4}$ Abs. 1 LV ganz besondere Bedeutung zu.

Zum Rechtsstaatsprinzip gehört die selbstverständliche Gebundenheit jedes Bürgers an das verfassungsgemäß beschlossene Gesetz. (Stern, Das Staatsrecht der Bundesrepublik Deutschland, Band I, 2. Aufl. 1984, $\mathbb{2 0}$ III 3 b). Um so mehr müssen sich gewählte Abgeordnete, denen selbst gesetzgebende Gewalt anvertraut ist, an ordnungsgemäß ergangene Normen wie das Volkszählungsgesetz 1987 und die weiteren mit ihm in Zusammenhang stehenden Vorschriften halten.

Die Tatsache, daß es sich hier im wesentlichen um Bundesgesetzgebung handelt, während die Antragsteller dem Landtag von Baden-Württemberg angehören, berührt ihre verfassungsmäßige Gesetzesbefolgungspflicht nicht. Zwar obliegt die Aufsicht über die ordnungsgemäße Durchführung von Bundesrecht durch die Länder nach Art. 84, 85 GG der Bundesregierung. Das ändert nichts daran, daß es eine grobe Verkennung ihrer verfassungsmäßigen Rechte und Pflichten als Abgeordnete und Fraktionen und damit eine Bedrohung der öfentlichen Sicherheit darstellt, wenn die Antragsteller memen, ihr parlamentarischer Status nach Art. 27 Abs. 3 LV schließe die Möglichkeit ein, sich an boykottierenden Maßnahmen gegen die Durchführung eines Bundesgesetzes zu beteiligen.

In dem Verhalten der Antragsteller liegt zugleich eine Verletzung des Demokratieprinzips im Sinne von Art. 23, 25 LV. Zu ihm gehört die Anerkennung der Legitimität demokratischer Entscheidungsfindung mit dem Mehrheitsprinzip und seiner Respektierung durch die Minderheit als zentralem Gedanken (Vgl, etwa Feuchte ( $\mathrm{Hg}$. ), Verfassung des Landes BadenWürttemberg, 1987, Art. 25 , RdNr. 24 ff.). Indem die Antragsteller dazu beitragen wollten, einem zweifelsfrei geltenden Bundesgesetz unter Ausnutzung ihres parlamentarischen Status 
den Gehorsam zu verweigern, verstießen sie gegen die verfassungsmäßige Ordnung in Bund und Ländern, die das Demokratieprinzip einschließt und an die sie als an der Gesetzgebung beteiligte Parlamentarier nach Art. 25 Abs. 2 LV gebunden sind. Auch hierin liegt eine Bedrohung der öffentlichen Sicherheit, gegen die der Antragsgegner kraft seiner Polizeigewalt im Sitzungsgebäude des Landtags nach Art. 32 Abs. 2 LV vorgehen konnte.

Die Tatsache, daß die verletzten Verfassungsnormen nicht straf- oder bußbewehrt sind, ändert an der polizeırechtlichen Beurteilung nichts. Eine Bedrohung der öffentlichen Sicherheit ist bereits beim Verstoß gegen geltende Normen der Rechtsordnung als solche gegeben, unabhängig davon, ob noch eine anderweitige Ahndung vorgesehen ist (Drews/Wacke/Vogel/Martens, Gefahrenabwehr, 9. Aufl. 1986, S. 236). Das gilt ganz besonders im Falle von Verfassungsnormen.

3. Da die Bedrohung der öffentlichen Sicherheit durch das Verhalten der Antragsteller bereits in Gestalt der Verletzung der verfassungsmäßigen Ordnung gegeben war und dies den Antragsgegner zu seinem polizeilichen Vorgehen nach Art. 32 Abs. 2 LV berechtigte, bedarf es hier keines Eingehens auf die von den Beteiligten angesprochenen Fragen, ob die beabsichtigte Benutzung des »Zählsorge-Telefons« im Sinne der Flugblätter den Auskunftspflichten nach SS $11 \mathrm{ff}$. Volkszählungsgesetz 1987 widersprochen habe und eine Ordnungswidrigkett nach $\$ S 1$, 23 Bundesstatistikgesetz gewesen seı. Gleiches gilt für die behauptete Annahme enner Ordnungswidrigkeit im Sinne von $\$ 116$ OWiG durch die Verbreitung des "Bürgerflugblattes und die ebenfalls vom Antragsgegner geäußerte Auffassung, die erfolgte bzw. beabsichtigte Belehrung anfragender Zähler/innen durch die Antragsteller am "Zählsorge-Telefon « stelle eine unerlaubte Rechtsberatung im Sinne von Art. $1 \$ 1$ Abs. 1 S. I Rechtsberatungsgesetz und damit eine Ordnungswidrigkeit nach Art. I $\$ 8$ Abs. 1 S. x RBerG dar. Obwohl schon auf den ersten Blick vieles dafür sprechen dürfte, daß die Antragsteller zumindest auch gegen Normen des Volkszählungs- und Statistikrechtes verstoßen haben, bedarf diese Frage hier im Verfahren vor dem Staatsgerichtshof keiner abschließenden Klärung. Zwar hat der Antragsgegner seinerseits in seinem Schreiben vom 12.3.1987 an den Fraktionsvorsitzenden der Grünen auf die Begehung von Ordnungswidrigkeiten mit abgestellt. Seine wesentliche Feststellung in diesem Schreiben, "daß die Telefonanlage des Landtags nicht bestimmungsgemäß gebraucht wird «, wurde aber zugletch von den oben ausgeführten verfassungsrechtlichen Erwägungen getragen. Das läßt sich mit hinreichender Sicherheit erkennen, sowohl aus dem Gesamtzusammenhang des Schreibens vom 12.3.1987, aus dessen Verbindung mit dem vorangegangenen Gespräch zwıschen dem Landtagspräsidenten und dem Fraktionsvorsitzenden der Grünen und aus dem ersten Schreiben des Antragsgegners vom 24.2.1987, in dem er u. a. darauf hinweist, "daß es ... mit dem Selbstverständnis eines Abgeordneten nicht vereinbart werden kann, den Aufruf zu unterstützen, die bevorstehende Volkszählung zu boykottieren und damit zur Nichtbeachtung eines Gesetzes aufzufordern.« [...

\section{Biggi Bender Stichworte zum »Zählsorge«-Urteil}

Zwar folgte das Gericht nicht der Argumentation des Landtagspräsidenten. Nach seiner Auffassung handelte es sich bei der Sperrung des »Zählsorgetelefons" lediglich um eine Maßnahme in Ausübung einer »Verwaltungskompetenz«, durch die der »bestimmungsgemäße Gebrauch « des Telefons sichergestellt werde. Eine solche $\mathrm{Maßnahme} \mathrm{berühre} \mathrm{den} \mathrm{Abgeordneten} \mathrm{nicht} \mathrm{in} \mathrm{seinem} \mathrm{Status,} \mathrm{bedürfe} \mathrm{also} \mathrm{keiner}$ besonderen Ermächtigung.

Das wäre sie dann gewesen, die alte Unterscheidung zwischen Grund- und Betriebsverhältnis, die Rechtsfigur des besonderen Gewaltverhältnisses, erdacht für Strafgefangene, BeamtInnen und SchülerInnen, angewendet auf das Verhältnis zwischen dem von der Mehrheit gewählten Parlamentspräsidenten und »seinen« Landtagsabgeordneten, oder besser gesagt den Angehörigen einer Minderheitsfraktion. Demokratietheoretisch eine gewiß interessante Vorstellung, die Bände spricht über das Demokratieverständnis jener, die sie zu ihrer Handlungsgrundlage erklärten. 
Das Urteil ist in mehrfacher Hinsicht erschreckend, denn hinter der konkreten Auswirkung, daß die vorgenommene Sperrung des Zählsorgetelefons gebilligt wurde, scheinen die ideologischen Grundlagen auf, die künftig Eingriffe anderen Ausmaßes ermöglichen könnten.

I. Ausgesprochen wird in der Entscheidung ein verfassungsrechtliches Verdikt über den zivilen Ungehorsam - eigentlich verstanden als die bewußte und offene Verletzung einzelner Gesetze unter Inkaufnahme der Sanktionen, als ein Mittel zur Überzeugung der Mehrheit, daß die betreffende Regel geändert werden müsse. Eine solche Gesetzesverletzung wird zum Bruch der verfassungsmäßigen Ordnung hochstilisiert, ein mögliches Auseinanderklaffen von Legalität und Legitimität staatlicher Entscheidungen schlicht ignoriert. Damit muß selbst der Protest gegen ein zunächst wirksames, später als verfassungswidrig aufgehobenes Gesetz oder gegen eine entsprechende Entscheidung (VZG 83, Teststrecke Boxberg) ein Verfassungsverstoß sein - ein Begriff von Demokratie, in der das »dixi« »des " Gesetzgebers an die Stelle der prozeßhaften Begegnung konfligierender Interessen tritt. Da sich gewaltfreie Aktionsgruppen etwa der Friedensbewegung wie auch die grüne Partei in ihrem Programm zum Mittel des zivilen Ungehorsams bekennen, trifft sie tendenziell der hier ausgesprochene Makel der Verfassungsfeindlichkeit.

2. Eher komische Züge trägt die Entdeckung einer »besonderen Gehorsamspflicht « von Abgeordneten gegenüber Gesetzen. Wer eine solche Pflicht auch gegenüber Vorschriften annimmt, an deren Zustandekommen der/die betreffenden Abgeordnete wie hier schon mangels Landeskompetenz gar nicht beteiligt war, müßte konsequenterweise entsprechende Sanktionen fordern. Also etwa die Abschaffung von Immunität und Indemnität als ersten Schritt, als weiteren die Erhöhung von Bußen und Strafen für Gesetzesverletzungen bei Abgeordneten und, vielleicht zusätzlich, den Ausschluß aus dem Parlament bei Rechtsverstößen - fragt sich bloß, wieviele parteispendenerfahrene Abgeordnete dann noch ihren Sitz hätten ... Soll die Beteiligung an einem Verfahren eine besondere Bindungswirkung entfalten, dann müßten konsequenterweise hier lebende AusländerInnen, die nicht einmal über das Wahlrecht Einfluß auf staatliche Entscheidungen nehmen können, völlig frei sein von der Pflicht zur Gesetzesbefolgung. Ein Aspekt des Urteils, der ganz neue Perspektiven eröffnet.

3. In der Entscheidung werden Methoden des zivilen Ungehorsams gleichgesetzt mit der Öffentlichkeitsarbeit, in diesem Falle einer Landtagsfraktion, zu einer umstrittenen staatlichen Maßnahme, hier der Volkszählung. Mag es schon zweifelhaft sein, ob die Volkszählungsboykottbewegung mit ihrer Orientierung auf das ganze legale Ausschöpfen des Rechtsweges wirklich auf zivilen Ungehorsam zielte, so ist in concreto jedenfalls nichts ersichtlich, was die Einrichtung eines Infotelefons zum Akt des zivilen Ungehorsams machen würde - es sei denn, es kommt nur auf die falsche Gesinnung an (»daß die boykottunterstützende Haltung der ,Grünen ‘... regelmäßig sichtbar würde«). So wird eine Eingriffsschwelle vorverlagert auf den (überdies "passiven «) Versuch, politische Öffentlichkeit zu schaffen.

4. Eine konkrete Eingriffsermächtigung, hier die Polizeigewalt des Landtagspräsidenten, wird einschlägig durch die gezielte Verbindung von Polizei- und Verfassungsrecht. Für die Prüfung der polizeirechtlichen Eingriffsvoraussetzungen hätte es einer Beweisaufnahme bedurft, um nachzuweisen, daß am Zählsorgetelefon mindestens Ordnungswidrigkeiten in Gestalt von Boykottaufrufen (die als Anstiftung jeweils einer Haupttat bedurft hätten!) begangen worden waren. Statt dessen stellt das Gericht lapidar fest, daß »die Pflicht, sich an die elementaren Verfassungsgrundsätze zu halten«, verletzt sei durch die »boykottunterstützende Haltung der Fraktion « und das Vorgehen des Landtagspräsidenten »im öffentlichen Interesse 
geboten " gewesen sei. Ein Novum in der Dogmatik des Polizeirechts, das nicht umsonst fest umrissene Eingriffstatbestände normiert - die polizeiliche Generalklausel als allgemeine Ermächtigung zur Durchsetzung vermeintlicher Loyalitätspflichten?

Den Schluß des Urteils ziert die salvatorische Klausel, wonach die Ausübung der Polizeigewalt gegen Abgeordnete »außergewöhnlich« zu sein habe. Eine notwendige Klarstellung auch zur Sicherung der Effizienz der Landtagsverwaltung; denn wer will schon, daß künftig die Untergebenen des Präsidenten tage- und nächtelang durch alle Fraktionsräume schleichen, um die verfassungsgemäße gesetzesbefolgende und gesinnungsrichtige Verwendung von Kopierern, Kulis und Computern zu kontrollieren? Das wird also nicht passieren. Aber, und das ist bitterernst, künftig hängt über der politischen Informationsarbeit in und außerhalb des Parlaments das Damoklesschwert von Eingriffen zugunsten »der Legitimität demokratischer Entscheidungsfindung nach dem Mehrheitsprinzip«.

\section{Thomas Ziegler/Dieter Hummel Ausgezählt?}

Zum Stand der rechtlichen Auseinandersetzung um die Volkszäblung 1987

Ein Jahr nach Beginn der von Anfang an umstrittenen bundesdeutschen Totalerhebung 1987 ruft das Stichwort "Volkszählung" unter jenen Juristen und Rechtsanwälten, die zur Wahrnehmung der Rechte der einstmals umfangreichen Schar von Zensusgegnern ausgezogen waren, zumeist lediglich noch gequälte Reaktionen hervor. Nicht ohne Grund: Mit einer Lawine von Verfahren waren die Instanzen der Verwaltungsgerichtsbarkeit zunächst bundesweit bemüht worden; demgegenüber hat die - wie es scheinen mag - geschlossene Phalanx der Verwaltungsrichter nahezu ausnahmslos alle Einwände und Verfahren gegen die Erhebungsmaschinerie ${ }^{1}$ unerbittlich abblitzen lassen.

An diskutablen und ernstzunehmenden Einwänden gegen die Verfassungs-, Gesetzund Verhältnismäßigkeit der Durchführungsregelungen für die Volkszählung 1987 herrschte zunächst kein Mangel. ${ }^{2}$ Zudem war die Wahrnehmung rechtlichen Gehörs von vornherein eröffnet: Die Anrufung des Bundesverfassungsgerichts im Wege der Verfassungsbeschwerde - nach Erschöpfung des verwaltungsgerichtlichen Rechtsweges gemäß $₫ 80$ Abs. 5 VwGO zur grundrechtsbezogenen Überprüfung der im Rahmen einer Volkszählung eingeforderten Auskunftspflichten - ist bereits durch das »Volkszählungs «urteil des Bundesverfassungsgerichtes vom 15. 1 2. $1983^{3}$ unter Hinweis auf frühere Entscheidungen des $\mathrm{BVerfG}^{4}$ ausdrücklich für zulässig erklärt worden. Den mit der Durchführung der Volkszählung 1987 befaßten Institutionen wurde weiter durch Beschluß des BVerfG vom 4.7.1987 "nahegelegt«, "für die Dauer des vorläufigen Rechtsschutzverfahrens (...) von Maßnahmen des Verwaltungszwanges oder der Verfolgung einer etwa gegebenen Ordnungswidrigkeit nach

1 Als solide begründete Ausnahme vgl. VG Wiesbaden, Beschluß vom 7.9.1987, Az. IV H 738/87 (Verfassungswidrıgkeıt der Trennungsregelungen) - nıcht rechtskräftıg.

2 Vgl. hierzu: Rottmann, KJ I987, $77 \mathrm{ff}$

3 BVerfGE $65,1 / 37 \mathrm{f}$

4 BVerfGE si, I30/I $38 \mathrm{ff}$; 53, 30/49/52

5 Az. I BvR 620/87, NJW 1987,2219 
$\$ 23$ Abs. I BStatG abzusehen ( $\$ 47$ Abs. I OWiG), soweit die Auskunft mit Rücksicht auf ein vorläufiges Rechtsschutzverfahren nicht (rechtzeitig) erteilt wird «.

Mit dieser Entscheidung einerseits gegen Zwangsmaßnahmen abgesichert, andererseits bedingt durch regelmäßig flüssig bis zu den Oberverwaltungsgerichten bzw. Verwaltungsgerichtshöfen durchentschiedene Eilverfahren - auf Wiederherstellung der aufschiebenden Wirkung der Widersprüche und Anfechtungsklagen gegen Heranziehungsbescheide gemäß $\ 80$ Abs. s VwGO, haben die einzelnen Einwände gegen den Zensus dem BVerfG verhältnismäßig frühzeitig zur Entscheidung vorgelegen. Die dort mit den einschlägigen Prüfungen befaßte r. Kammer des Ersten Senats kann zwischenzeitlich mit einer respektablen Aufstellung all jener Gründe aufwarten, die dort nunmehr den Heldentod gefunden haben:

Nach der Rechtsprechung des höchsten deutschen Gerichts geklärt ist bisher, daß - die nach dem Volkszählungsgesetz durchzuführende Totalerhebung nach dem Stand der Methodendiskussion beim Abschluß des Gesetzgebungsverfahrens für das Volkszählungsgesetz 1987 als erforderlich und verhältnismäßig angesehen werden durfte ${ }^{6}$;

- die nach $₫$ is Abs. I VZG 1987 vorgeschriebene Trennung als entbehrlich angesehen werden kann, da bis zu dem dort normierten Trennungszeitpunkt die Erhebungsbögen der Gebäudevorerbebung gemäß \Is Abs. 2 VZG 1987 zu vernichten sind und unter dieser Voraussetzung letztere keinen verfassungsrechtlichen Bedenken begegnet';

- die Vorschriften des Volkszählungsgesetzes über die gebotene Anonymısterung und das Verbot einer Retdentifizuerung der erhobenen Daten sowohl hinreichend bestimmt - normenklar - als auch für einen wirksamen Schutz der durch die Volkszählung betroffenen Grundrechte inhaltlich ausreichend $\operatorname{sind}^{8}$;

- die Bestimmungen über die Bildung von Gliederungseinheiten - Blockseiten - aus verfassungsrechtlicher Sicht nicht zu beanstanden sind ${ }^{9}$;

- keine verfassungsrechtlichen Bedenken hinsichtlich der Nichtverfügbarkeit von Auswertungsprogrammen sowie

- des gemäß $\$$ I4 Abs. I Satz 3 VZG 1987 vorgesehenen Landesgesetzes bereits während der Erhebungsphase des Volkszählungsverfahrens bestehen ${ }^{10}$;

- verfassungsrechtlich ausreichende Regelungen hinsichtlich der Organisationspapiere und deren Sicherung gegen unbefugten Gebrauch vorhanden sind";

- das gesetzliche Auskunftsverlangen grundrechtsgeschützte Positionen nicht verletzt, soweit es sich auf die Fragen im Personenbogen nach der Arbeitsstätte und der beruflichen Tätigkeit bezieht, selbst wenn der Auskunftspflichtige sich selbständig auf dem eigenen Grundstück betätigt und/oder einen in der Gliederungseinheit Blockseite nur einmal anzutreffenden Beruf ausübt - Fragen 12, 16 und $17^{-12}$; - die in $\int 15$ Abs. I und 2 VZG 1987 normierten Regelungen, wonach die Erhe-

6 Beschluß des BVerfG vom 28.9.1987 (Az. I BvR 1063/87), BayVBl 1987, 689ff., NJW 1988, 962; Beschluß des VGH BaWü vom 27.8. 1987 (Az. Z $10 \mathrm{~S}_{31} / 87$ ).

7 Beschluß des BVerfG vom 26.5.1987 (Az. I BvR 586/87), NJW 1987, I689.

8 Beschlüsse des BVerfG vom 24.9. 1987 (Az. I BvR 970/87), NJW I987, 280s ff,; vom 28.9. 1987, a.a. O.;

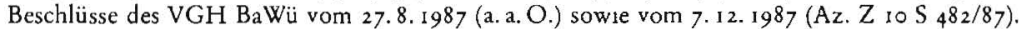

9 Beschluß des BVerfG vom 24.9. 1987 (a. a. O.); Beschluß des VGH BaWü vom 16.9. 1987 (Az. Z $10 \mathrm{~S}$ $40 / 87)$.

ro Beschlüsse des BVerfG vom 24.9. 1987 (a.a.O.), vom 25.9. 1987 (Az. I BvR 936/87). Beschluß des VGH BaWü vom 27.8. 1987 (a.a.O.) sowıe vom 7.12.1987 (a.a.O.).

11 Beschluß des BVerfG vom 24.9.1987 (a.a. O.); Beschluß des VGH BaWü vom 27.8.1987 (a. a. O.),

I2 Beschluß des BVerfG vom 18. 12.1987 (I BvR 962/87); Beschlüsse des VGH BaWü vom 9.11. 1987 (Az.

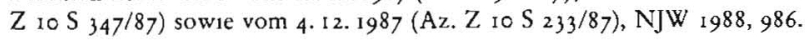


bungs- von den Hilfsmerkmalen erst nach einer Eingangskontrolle bei den statistischen Landesämtern getrennt und die Erhebungsunterlagen zum frühestmöglichen Zeitpunkt, spätestens zwei Wochen nach Feststellung der amtlichen Einwohnerzahl des Landes zu vernichten sind, mit dem Grundgesetz vereinbar bleiben ${ }^{13}$, sowie daß - verfassungsrechtliche Bedenken auch nicht gegen die Bearbeitung von Rechtsbehelfen und verwaltungsgerichtlichen Verfahren oder von Maßnahmen zur Durchsetzung der Auskunftspflicht in Sachen Volkszählung durch Behörden des allgemeinen Verwaltungsvollzugs bestehen ${ }^{14}$.

Rechtskräftige Beschlußlage der Verwaltungsgerichtsbarkeit ist darüberhinaus, daß - gegen die Regelung gemäß \ I A Abs. I VZG 1987, nach der die Meldebehörden den Erhebungsstellen zur Organisation der Zählung die in der angeführten Norm benannten Daten aus dem Melderegister übermitteln dürfen, keine verfassungsrechtlichen Einwendungen bestehen 's;

- das Volkszählungsgesetz und die zu ihm ergangenen landesrechtlichen Durchführungsbestimmungen verfassungsrechtlich ausreichende Regelungen für die räumliche, organisatorische und personelle Trennung der Erhebungs- von den übrigen Verwaltungsstellen vorschreiben ${ }^{16}$;

- der tageweise Einsatz von Gemeindebediensteten in Erhebungsstellen und ihre anschließende Rückkebr in den Verwaltungsvollzug sowohl diesen gesetzlichen als auch den verfassungsrechtlichen Anforderungen an die Abschottung der Volkszählung von der übrigen Verwaltungstätigkeit entsprechen sollen ${ }^{17}$;

- gegen den Einsatz regionaler Rechenzentren zur Durchführung der Volkszählung aus verfassungsrechtlicher Sicht keine Einwände bestehen ${ }^{18}$;

- die gesetzliche Auskunftspflicht nach \I2 Abs. I VZG I987, soweit sie noch nicht erfüllt ist, auch dann fortbesteht, wenn die örtlicbe Erbebungsstelle nach Ablieferung der Erhebungsunterlagen bei den statistischen Landesämtern als ständige Einrichtung geschlossen worden ist ${ }^{\mathrm{r}}$;

- eine örtliche Regelung, nach der Erbebungsunterlagen, die erst nach Schließung der Erhebungsstelle eingehen, unter Verschluß genommen und an einem vorher bestimmten Tag von einem an diesem Tag eigens dafür abgestellten Bediensteten bearbeitet werden, den gesetzlichen und verfassungsrechtlichen Erfordernissen entspricht ${ }^{20}$ sowie schließlich, daß

- die Frage im Personenbogen nach einer weiteren Wohnung im Bundesgebiet sowie die dort verlangte Differenzierung für Verheiratete, nicht dauernd getrennt Lebenden und alle übrigen Personen - Frage 6 - grundrechtsgeschützte Rechtspositionen nicht verletzt ${ }^{21}$.

»Gezählt wird alles - Beschwerde zwecklos« hat die Volkszählungsfachfrau der

13 Beschluß des BVerfG vom 18. 12.1987 (a. a. O.); Beschluß des VGH BaWü vom 7. I 2. 1987 (a. a. O.).

14 Beschluß des BVerfG vom 18.12.1987 (a.a.O.).

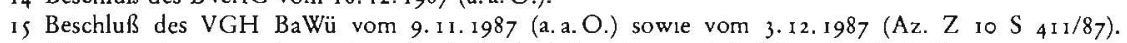
Oberverwaltungsgerichte anderer Bundesländer haben diese und die folgenden Rechtsfragen im wesentlichen ebenso beurteilt:

Bayerıscher VGH, Beschlüsse vom 1.7.1987 (NJW x987, 2831), 21.8.1987 (NJW 1987, 2836), 3.9.1987 (BayVBI. 1987, 660) und vom 10.9.1987 (Az. s Cs 87.02285).

Hessischer VGH, Normenkontrollbeschluß vom 2. 10. 1987, DVBl. I987, 1212 ; OVG Rhemland-Pfalz, Beschluß vom 16.7.1987, NJW 1987, 2533 sowse OVG Lüneburg, Beschlüsse vom I2.8.1987 (Az. 13 OVG $\left.B_{12} / 87\right)$ und vom 14.8 .1987 , NJW 1987,2834 .

16 Beschluß des VGH BaWü vom 29.4- 1987 (Az. Z 10 S 956/87), NJW 1987, $1716 \mathrm{f}$

17 Beschluß des VGH BaWü vom 2r. 5. 1987 (Az. Z I0 S $1 / 87$ ), NJW 1987, $1717 \mathrm{f}$

18 Beschluß des VGH BaWü vom 7.9.1987 (Az. Z io S 28/87), NJW 1987, $2835 \mathrm{f}$.

19 Beschluß des VGH BaWü vom 24. I1. 1987 (Az. Z $10 S_{322 / 87}$ ).

20 Beschluß des VGH BaWü rom 3.12.1987, a. a.O.

2 I Beschluß des VGH BaWü rom 6. 10. 1987 (Az. Z 1o S 228/87). 
"tageszeitung ", Vera Gaserow, den Pressebericht ${ }^{22}$ über den jüngsten Abweisungsbeschluß des $\mathrm{BVerfG}^{23}$ resigniert betitelt. Ende der juristischen Fahnenstange?

Gerade die vorgenannte Entscheidung des BVerfG vom I8.12.1987 bietet sich hingegen als anschauliches Beispiel des Gegenteils an: Der genannte Beschluß hatte zum Gegenstand die Reidentifikations-Befürchtungen eines Beschwerdeführers aus dem erstinstanzlichen Zuständigkeitsbereich des VG Stade, der "in Alleinpraxis ohne Hilfskräfte als Rechtsanwalt tätig « und dessen »Arbeitsstätte (...) auf dem gleichen Grundstück wie seine Wohnung" angesiedelt ist.

Derartige Konstellationen führen zu der Problematik, daß die zu den Hilfsmerkmalen Straße und Hausnummer der Haupt- oder Nebenwohnung sowie Familiennamen des Auskunftspflichtigen ( $\$ 8$ Abs. I Nr. I VZG 1987) zu erteilenden Auskünfte ganz oder teilweise übereinstimmen mit jenen zu anderen Hilfmerkmalen (Name der Arbeitsstätte: $\ 8$ Abs. 1 Nr. I VZG 1987) oder Erhebungsmerkmalen (Name und Hausnummer der Arbeitsstätte: $₫ 5$ Nr. 7 VZG 1987). Diese Daten ergeben sich zudem unmittelbar und eindeutig aus den Angaben auf dem Personenbogen, insbesondere zu den Fragen 12, 14, I5 und 17; Reidentifikation also recht einfach möglich.

Das BVerfG bescheinigt dem Beschwerdeführer zwar die grundsätzliche „Grundrechtsrelevanz dieser Besonderheit«, ]äßt die aufgezeigten erhöhten Gefahren einer Reidentifikation und damit für das Recht auf informationelle Selbstbestimmung im Ergebnis jedoch zurücktreten hinter den Anforderungen eines möglichst hohen Grades "an Genauigkeit (...) der erhobenen Daten « sowie gegenüber ansonsten erforderlichen »organisatorischen und verfahrensrechtlichen Vorkehrungen (...), die mit einem erheblichen, von der Gesellschaft vernünftigerweise nicht zu beanspruchenden Mehraufwand an nur begrenzt verfügbaren öffentlichen Mitteln verbunden sind " (BVerfG, a. a. O.).

Immerhin hat es sich aber das BVerfG bei dieser Gelegenheit nicht nehmen lassen, die Übernahme jener Daten, die zur maschinellen Weiterverarbeitung auf Datenträgern vorgesehen sind, lediglich unter der Voraussetzung für verfassungsrechtlich zulässig zu erklären, daß bei einer Identität von Wohnungs- und Arbeitsstättenanschrift eine Speicherung der Erhebungsmerkmale "Straße und Hausnummer der Arbeitsstätte" zu unterbleiben hat. "Der Verzicht auf diese Speicherung ist dabei den statistischen Landesämtern nicht freigestellt, sondern von Verfassungs wegen (...) geboten $*$.

Gezählt wird "alles«? Zwar nicht der Zweck, aber doch immerhin der (Teil-)Erfolg so manchen - auf den ersten Blick vergeblichen - Rechtsmittels hat sich, und dies verdient, als Zwischenbilanz herausgestellt zu werden, für die vorgesehenen Verarbeitungspraktiken bis weit hinein in die Verwertung bei den statistischen Landesämtern eben doch, und nicht nur in Details, ausgewirkt.

Der Anknüpfungspunkt eines ebenso klassischen wie interessanten Fallbeispiels für eine - bundesweit nahezu unbemerkt - inzwischen heiß umkämpfte Problematik in Sachen Volkszählung findet sich pikanterweise ebenfalls in jenem bereits angeführten Beschluß des BVerfG vom I8. 12.1987 - nur wenige Abschnitte nach dem zuletzt gewürdigten:

Dort wird die aus der Regelung im $\$ is Abs. 2 VZG 1987 resultierende Frage angesprochen, »ob die im Gesetzgebungsverfahren gegebene Begründung für die Anbindung des spätesten Löschungszeitpunktes an die Feststellung der amtlichen Bevölkerungszahl durch die statistischen Ämter (vgl. BT-Drucks. $10 / 2814$, S. 25 ) die

22 die tageszettung vom 2. 1. 1988

23 Vgl. Fn. 12. 
Aufbewahrung auch der Personenbögen, deren Inhalt dem Statistikgeheimnis $(\$$ I6 BStatG) unterliegt, als für statistische Zwecke erforderlich zu rechtfertigen vermag, weil sie als Beweismittel für etwa mögliche Verwaltungsstreitverfahren um die Feststellung der amtlichen Bevölkerungszahl in Betracht kommen könnten.« $\mathrm{Zu}$ einer »abschließenden Beurteilung " dieser Problematik hat sich das BVerfG »indes mangels entsprechender Rüge « nicht bemüßigt gefühlt.

War da ein sich aufdrängender, sogar möglicherweise entscheidungserheblicher Gesichtspunkt dem betreffenden unglücklichen Beschwerdeführer, immerhin Rechtsanwalt, entgangen? Die Erklärung hierfür ist allerdings alles andere als naheliegend: Das BVerfG hat zu dieser Problematik seine Entscheidung offen halten können, da dem norddeutschen Beschwerdeführer - über diese Entfernung hinweg verständlich - eine Entwicklung verborgen geblieben sein mußte, die in der badenwürttembergischen Provinz, genauer gesagt am Verwaltungsgericht in der ehemals fürstlich-hohenzollerischen Enklaven-Residenz Sigmaringen ihren Ausgang genommen hat: Den dort wie anderswo mit hunderten von Verfahren auf Wiederherstellung der aufschiebenden Wirkung konfrontierten Kammern war ihrerseits nicht entgangen, daß mit zwei durch das BVerfG im Herbst 1987 ergangenen einschlägigen Entscheidungen ${ }^{24}$ den für die Durchführung der Erhebung verantwortlichen Behörden zwar die durch den Bundesgesetzgeber eingeräumten Spielräume hinsichtlich der Trennungs-, Löschungs- und Vernichtungsgebote für die Organisationspapiere sowie die Hilfsmerkmale im Sinne des $\$ is Abs. I "unverzüglich «bzw. gemäß Abs. 2 und 3 "zum frühestmöglichen Zeitpunkt, spätestens zwei Wochen nach Feststellung der amtlichen Bevölkerungszahl des Landes « eingeräumt und bestätigt worden war. In diesem Zusammenhang hatte das BVerfG jedoch seine Rechtsauffassung weitergehend differenziert:

"Die Feststellung der amtlichen Bevölkerungszahl des Landes kennzeichnet dabei nach dem eindeutigen Gesetzeswortlaut nicht den Regelzeitpunkt, sondern den spätesten Zeitpunkt der Löschung oder Vernıchtung; die statistischen Landesämter sind gehalten, für jede der Erhebungsunterlagen den jeweils frühestmöglichen Zeitpunkt zu ermitteln und die Vernichtung oder Löschung zu diesem Zeitpunkt vorzunehmen" (BVerfG a. a. O.). Die Kontrolle für die Beachtung dieser Pflichten obliege dabei, neben den Datenschutzbeauftragten, »den Gerichten namentlich der Verwaltungsgerichtsbarkeit «, und zwar »in vollem Umfang «. Dabei bilden »Art und Geschwindigkeit der Aufbereitung und ihrer Organisation (...) keine verbindlichen, etwa die Gerichte bindenden, tatsächlichen Vorgaben der statistischen Landesämter, sondern haben sich ihrerseits am Gebot frühestmöglicher Löschung und Vernichtung zu orientieren.« (BVerfG, a. a. O.)

Nachdem durch die beiden genannten Beschlüsse die Einhaltung und Überwachung der in $\$$ is Abs. 2 bis 4 VZG 1987 geregelten Löschungs- und Vernichtungsgebote bei den statistischen Landesämtern dem besonderen Augenmerk der Verwaltungsgerichtsbarkeit nunmehr nachdrücklich anempfohlen worden war, sind durch das VG Sigmaringen konsequenterweise umgehend - das Anforderungsschreiben trägt den Vermerk: Per Eilboten/Eilt sehr!/Bitte sofort vorlegen! - die entsprechenden diesbezüglichen Auskünfte bei dem Statistischen Landesamt Baden-Württemberg angefordert worden. In einer von dort aus dem Verwaltungsgericht vorgelegten Stellungnahme vom 9. 10.1987, in der im übrigen auf eine vertiefendere Darlegung des Landesamtes gegenüber dem - offenbar ebenfalls entsprechende Auskünfte begehrenden - Ersten Senat des BVerfG ${ }^{25}$ gleichen Datums verwiesen wird, ist durch das Statistische Landesamt Baden-Württemberg hinsichtlich der betreffenden Vernichtungszeitpunkte unter anderem folgende amtliche Auskunft gegeben worden: »Der

24 Beschluß des BVerfG vom 24.9.1987 (a.a. O.) sowse vom 28.9.1987 (a.a. O.).

25 Zum dortigen Az. I BvR ${ }_{1043} / 87$. 
Haushaltsmantelbogen, der Personenbogen und der Wohnungsbogen mit Gebäudeangaben werden zwei Wochen nach Feststellung der bestandskräftigen Einwohnerzahl vernichtet. ${ }^{26}$

Diese Handhabung begründete das Statistische Landesamt wie folgt:

"Der jeweilige Vernichtungszeitpunkt richtet sich (...) vor allem nach Sinn und Zweck der Volkszählung, verläßliche Datengrundlagen zu liefern. Von maßgeblicher Bedeutung für die Allgemeinheit ist $u$. a. die Feststellung der amtlichen Bevölkerungszahlen von Bund, Ländern und Gemeinden im Rahmen der Volkszählung 1987. (...) Insbesondere die amtliche Bevölkerungszahl der Gemeınden ist maßgebliche Ermittlungsgrundlage z. B. für den Finanzausgleich und hat als Basis für die Bevölkerungsfortschreibung weit über die Volkszählung 1987 hinaus grundlegende Bedeutung (vgl. hierzu auch BT-Drucksache $10 / 2814$, S. 12). Aufgrund dieser Bedeutung der Bevölkerungszahlen (...) wird mit einer Reihe von Anfechtungen seitens der Gemeinden gerechnet, wenn die aufgrund der Volkszählung 1987 ermittelten Bevölkerungszahlen gegenüber den bisherigen Zahlen niedrigere Werte ausweisen. Gerichtliche Auseinandersetzungen sind hierbei ebenfalls nicht auszuschließen. Den statistischen Landesämtern wiederum obliegt die Beweislast für die Richtıgkeit der festgestellten Ergebnisse (vgl. BTDrucksache $10 / 2814$, S. 25). [...] Im Falle der Auseinandersetzung über die festgestellte Bevölkerungszahl ... kann es zum Nachweis der Richtigkeit des festgestellten Ergebnisses notwendig sein, die Erhebungsbogen, insbesondere die Wohnungs- und Personenbogen, insgesamt nochmals zu lesen und/oder die Regionallisten nochmals zu erfassen und die maschinellen Arbeitsgänge zu wiederholen. « ${ }^{27}$

Gleichzeitig erbat das VG Sigmaringen eine Stellungnahme durch »den Landesbeauftragten für den Datenschutz Baden-Württemberg «. Die couragierte Landesdatenschutzbeauftragte Leuze legte daraufhin eine Beurteilung vor, die das Gebot einer möglichst frühzeitigen Anonymisierung ${ }^{28}$ ausschließlich unter der Voraussetzung als erfüllt ansieht, daß die betreffenden Erhebungsunterlagen »sukzessiv Gemeinde um Gemeinde « spätestens mit »Abschluß der Plausibilitätskontrollen« zu vernichten sind.

Dieser Rechtsauffassung folgend, haben - von insgesamt sieben Referaten - die r., die s. sowie die 6. Kammer des VG Sigmaringen für sämtliche dort anhängigen zulässigen Anträge - und damit nach Auskunft des Gerichtes für insgesamt etwa 900 Antragsteller - die Wiederherstellung der aufschiebenden Wirkung der betreffenden Widersprüche und Anfechtungsklagen angeordnet. In den Entscheidungsgründen der dort ergangenen Beschlüsse wird im wesentlichen darüberhinaus darauf abgehoben, daß durch das Statistische Landesamt versäumt worden sei, gemäß der Vorgabe des BVerfG für jede etnzelne der Erbebungsunterlagen den jeweils frühestmöglichen Zeitpunkt zu ermitteln; soweit ferner eine längere Aufbewahrungsdauer mit dem Erfordernis einer Beweisführung für nachfolgende Prozesse über die Feststellung der amtlichen Einwohnerzahl gerechtfertigt werde, handle es sich hierbei nicht mehr um "Zwecke der Volkszählung im Sinne der Vorschrift des \ I Abs. 2 VZG $1987^{29}$.

Die Zweitinstanz in Gestalt des sachbefaßten ro. Senats des VGH Baden-Württemberg reagierte umgehend: Noch vor Rechtshängigkeit der Beschwerdeanträge, der gebotenen Eile wegen in die Beschlußbegründung eines erstinstanzlich vor dem VG Karlsruhe anhängigen Antrages gemäß $₫ 80 \mathrm{Abs.5} \mathrm{VwGO}$ eingefügt, stellten die Mannheimer Richter klar: „Der Senat folgt dem VG Sigmaringen nicht. « ${ }^{30}$. Diese Entscheidung begründete der VGH im wesentlichen mit der Grundsatzabwägung, $\mathrm{da}$ hinter dem "Gebot, die maßgebenden statistischen Daten mit einem möglichst

26 Amtliche Auskunft des Statıstıschen Landesamtes Baden-Württemberg yom 9. 10. 1987. 27 S. Fn. 26.

28 BVerfGE 65, iff. $/ 40$.

29 Musterbeschlüsse vom I6. I1. 1987 und I9. I1. I987 ( $\mathrm{Z}$ I K I702/87, Z 5 K 90/87 und Z 6 K I I 36/87)

30 Musterbeschluß des VGH BaWü vom 7.12. 1987 (Az. Z $10 \mathrm{~S}_{482 / 87}$ ), NJW 1988, 988. 
hohen Grad an Genauigkeit und Wahrheitsgehalt festzustellen«, die Bedenken gegenüber einer längeren Aufbewahrungsdauer der Erhebungsunterlagen im Statistischen Landesamt, in dessen Verantwortungsbereich "Datenmißbrauch faktisch « ohnehin auszuschließen sei, zurückzutreten hätten.

Durch diese Beschlußlage wieder ermutigt und hierauf Bezug nehmend, sind durch die erstinstanzlich unterlegenen Gemeinden, Städte und Landkreise das Rechtsmittel der Beschwerde eingelegt und hierauf die Beschlüsse der Vorinstanz durch den Verwaltungsgerichtshof Baden-Württemberg zwischenzeitlich teilweise aufgehoben sowie die betreffenden Anträge auf Wiederherstellung der aufschiebenden Wirkung abgelehnt worden.

Um so mehr erstaunt haben dürfte die Richter des Mannheimer Senates, daß das BVerfG wiederum - und hier schließt sich der Kreis zu der eingangs angeführten dortigen Entscheidung - mit Beschluß vom 18. 12. 1987, also anschließend und in Kenntnis der Beschlußlage des Verwaltungsgerichtshofes diese nicht etwa bestätigt, sondern sich ausdrücklich einer späteren Entscheidung noch vorbehalten hat.

Durch diese "Einladung « ihrerseits aufgefordert, sind gegen die beispielsweise im Bereich des Landkreises Reutlingen bisher ergangenen Beschlüsse des VGH Mannheim durch die Antragsteller nahezu ausnahmslos Verfassungsbeschwerden eingelegt worden ${ }^{31}$. Zur Begründung der Verfassungsbeschwerden sind dabei mehrere Argumentationen ins Feld geführt worden:

- Es dürfte äußerst fragwürdig sein, ob allein die Feststellung der amtlichen Bevölkerungszahl als einer statıstıschen Größe - und damit wohl nur schwerlich als Verwaltungsakt zu qualifizieren - die für einen eventuellen Rechtsstreit zwischen Land und Gemeinden erforderliche Qualität eines Streitgegenstandes aufweisen kann. ${ }^{32}$

- Weiter bleibe die Rechtsansicht des Verwaltungsgerichtshofes eine plausible Erklärung dafür schuldig, wie die von dort aus zugunsten der Gemeinden unterstellten Möglichkeiten einer Rechtsmitteleinlegung gegen die amtliche Feststellung der Bevölkerungszahl im Hinblick auf die in $\$ 74$ VwGO normierten Klagefristen mit der andererseits in $\$$ Is Abs. 2 festgelegten Zeitspanne - »spätestens zwei Wochen nach Feststellung «! - zu vereinbaren sei.

- Die Suche nach dem Begriff des durch den Verwaltungsgerichtshof benannten "Feststellungsbescherdes" hinsichtlich der Bevölkerungszahl unter den Bestimmungen des Volkszählungsgesetzes bleibe vergeblich, wie auch dort in keiner Weise Regelungen ersichtlich sind, ob und ggf. unter welchen Voraussetzungen und welchen Beteiligten gegenüber ein solcher Bescheid zuzustellen wäre und schließlich in Bestandskraft erwachsen könnte.

- Rechtlichen Bedenken begegne ferner, in welcher Form die betreffenden schriftlichen Unterlagen in eventuelle Rechtsstreitigkeiten als Beweismittel eingeführt und verwertet werden sollen, ohne das in $\$ \times 6$ BStatG normierte Statistikgeheimnis zu umgehen, zumal die Abgabe einer schriftlichen Erklärung über einen bestimmten Sachverhalt durch die betreffende Behörde einen Urkundenbeweis nicht zu ersetzen vermag. ${ }^{33}$

- Ein von vornherein in Kauf genommenes Ausschöpfen der Löschungsfristen habe der Gesetzgeber lediglich bezüglich der Löschungsregelungen für Datenträger nach \ I I VZG 1987 vorgesehen, $\int$ is Abs. 6 VZG 1987; die Regelungen nach $\$ is Abs. 2

31 Az. I BvR 334/88, $385 / 88,489 / 88$. Mit Beschluß der I. Kammer v. 19. 4. 1988 wurden die Verfassungsbeschwerden allerdings nicht zur Entscheidung angenommen.

32 Verneinend: Der Landesbeauftragte für den Datenschutz in Baden-Württemberg, Stellungnahme vom 9. 10. 1987 (a.a.O.) S. $19 \mathrm{f}$

33 BVerwGE $39,36 \mathrm{f}$. 
bis s VZG 1987 stehen dagegen unter der - gleichsam vor die Klammer gezogenenMinimierungsklausel einer Vernichtung zum frühestmöglichen Zettpunkt.

- Und schließlich dürfte es aus verfassungsrechtlicher Sicht mehr als bedenklich sein, in Folge der möglicherweise durch eine einzıge Gemeinde bestrittenen Festsetzung ihrer Einwohnerzahl sämtliche im Rahmen der Volkszählung gewonnenen und weitergeleiteten Organisationspapiere und Hilfsmerkmale - mit vollem und direktem Personenbezug! - über die Dauer eines derartigen Rechtsstreites und damit über Jahre hinweg fortdauernd gespeichert und abrufbereit zu halten.

Als Nachwort sei aus dem Erlaß des Finanzministeriums Baden-Württemberg an die Erhebungsstellen vom 20. I. 1988 zitiert:

"Ziffer 2:

(...) die Verwertung nachgereichter Erhebungsunterlagen ist dem Statistischen Landesamt bis zum Abschluß der maschinellen Plausibilitätskontrollen der betreffenden Gemeinden möglich. Diese (...) werden voraussichtlich im Zeitraum März bis Oktober 1988 erfolgen. (...)

Ziffer 3:

Anhängige Rechtsbehelfsverfahren (...) erledigen sich mit Ablauf des letzten Verwertungszeitpunktes in der Hauptsache. Die Verfahren vor den Verwaltungsgerichten sind (...) für erledigt zu erklären. (...)《

\section{Wilhelm Steinmüller Volkszählung - Erfolg oder Mißerfolg? Eine Zwischenbilanz}

Von staatlicher Seite wird häufig behauptet, die Volkszählung 1987 sei ein fast hundertprozentiger Erfolg. Viele Boykottinitiativen haben gute Gründe für die Annahme des Gegenteils. Es ist an der Zeit, eine vorläufige Bilanz zu ziehen. Sie wird nicht nur erfreulich sein, wenn man die Zusammenhänge beachtet, in denen dieser Zensus geplant und durchgeführt worden ist.

\section{Erfolg des Volkszählungsboykotts?}

Wir müssen uns klar machen, daß Verwaltungen einen verfassungsüberdauernden langen Atem haben. Es leben noch Staatsdiener, die auf vier einander widersprechende Verfassungen den Beamteneid geschworen haben. Immerhin ist ein Gutteil dessen, was heute als Aufrüstung des westdeutschen Staatsapparats erscheint, bereits im Dritten Reich erarbeitet und (mangels Technik nur teilweise) realisiert worden so auch das wissenschaftliche Grundgerüst dieser Volkszählung.

Die ob der Hinhaltetaktik der Innenbehörden verständliche Resignation der Initiativen täuscht. Die Boykottbewegung hat in mehrfacher Hinsicht gestegt.

(I) Zunächst ist es völlig richtig, daß diese Volkszählung als Volkszählung im klassischen Sinn, nämlich als Totalerhebung, für die Statistiker nur "Datenschrott" gebracht hat, wie es Klaus Brunnstein auf den Punkt gebracht hat. Unter statistikwissenschaftlichen Gesichtspunkten ist diese Totalerhebung gescheitert, weil für zahlreiche Auswertungen unbrauchbar. Das ist das Verdienst der unerschöpflichen Phantasie der "sanften "Verweigerer, deren Früchte durch keine statistischen Bereinigungsmethoden mehr aus der Welt zu schaffen sind. 
(2) Sodann wird diese Volkszählung wohl die letzte ibrer Art sein. Ein Indiz dafür stammt aus einer unverdächtigen Quelle, nämlich der neuen EG-Richtlinie zur nächsten Volkszählung 1990. Sie sieht - nach den üblichen Worten über die absolute Unentbehrlichkeit der Totalerhebung - vor, daß die Niederlande und die Bundesrepublik keine Volkszählung im bisherigen Sinne mehr durchführen müssen. Woher kommt diese Sinnesänderung? Darauf ist sogleich einzugehen.

(3) $\mathrm{Zu}$ wenig, wenn man die deutsche Geschichte kennt, wird der politische Disziplinierungsverlust beachtet, den die "Volkserhebung gegen die Totalerhebung " erbracht hat. Hoimar von Ditfurth hat gemeint, der Staat wolle seine Angehörigen »vorführen«. Dieser circensische Ausdruck eines Bärenführerstaats trifft nicht die schlimmere Wirklichkeit. Es ging darum, den entmündigenden Untertanen-Gehorsam gegenüber der preußisch-deutschen Obrigkeit aus vordemokratischen Zeiten wiederherzustellen, auf lateinisch: zu restaurieren. Wenn nicht innerer Gehorsam gegenüber dem gottverordneten "Schwert Gottes zur Linken ", so sollte doch wenigstens Mitläufertum mit allen legalen und illegalen, jedoch obrigkeitlichen, Mitteln erpreßt werden - ein Ziel, das im Dritten Reich schon einmal erreicht schien. Es wurde um Längen verfehlt, gottlob. Dabei macht es vorerst wenig Unterschied, ob die Boykottbewegung derart undemokratischem Treiben Schwejk'sche Schläue oder bekennerhaften Widerstand entgegensetzte; wichtig war und ist für uns demokratieungewohnte Deutsche, daß dies überhaupt geschah und weiter geschieht.

Doch sollte man sich keinen Illusionen hingeben. Wie tief die Staatstreue der Deutschen geht, kann man daran ermessen, daß fast die gesamte bundesrepublikanische Presse zum ersten Mal seit 1933, durch Selbstzensur gleichgeschaltet, keine Öffentlichkeit mehr herstellen wollte, bis auf die unentbehrliche taz einerseits, die liberale ZEIT und den SPIEGEL (wenigstens teilweise) andererseits. Medienöffentlichkeit steht bis auf weiteres in Sachen Staatstreue nur noch beschränkt zur Verfügung. Illusionen in Richtung auf kritische Öffentlichkeit aus den 68er Jahren können getrost begraben werden. Die Forderung nach einem US-amerikanischen (und inzwischen wieder entschärften) »freedom of information act « (»Informationsfreiheitsgesetz«) bleibt unverzichtbar, hat aber nur Entlarvungsfunktion. Das will auch sagen, daß die Öffentlichkeitsfunktion zunehmend von gesellschaftlichen Gruppierungen wahrgenommen wird und wahrgenommen werden muß - um so mehr, je weiter sich die GRÜNEN im Sog ihrer Flügel und in der Faszination der Macht von ihrer historischen Aufgabe abtreiben lassen.

\section{Erfolg der Volkszählung?}

Diese Volkszählung hat allerdings für ihre Urheber einen Doppelerfolg erbracht, der in seiner Tragweite noch nicht abschätzbar ist. Warum eigentlich wird so langsam gezählt, warum werden die Bögen nicht verschickt? Das hat doch nicht nur finanzielle Gründe, etwa den teuren Verwaltungszwang einzusparen. Oder ist es nur Taktik? Einige Bundesländer zählen doch offensichtlich nicht mehr ernsthaft: Hessen, Bremen, Hamburg, Saargebiet. Und dennoch wird behauptet, die Zählung sei ein Erfolg. Ich glaube, daß das - leider - in doppelter Hinsicht zutrifft; aber in anderer, als dies von den Boykottinitiativen erwartet und vorausgesehen wurde.

(I) Man habe sichergestellt, daß die nötigen Daten für die EG »auf andere Weise « beigebracht werden, heißt es in der erwähnten EG-Richtlinie. Weiter: sie sei mit Zustimmung des Bundesstatistikamtes verabschiedet worden. Das kann doch nicht wahr sein - nach all den hehren Worten. Und dennoch: man braucht die alte Volkszählung in der Tat nicht mehr. Denn die Statistiker haben aus der Volkszählung ' 87 die unerläßlichen sechs Grunddaten erhalten, die sie brauchen, um darauf 
aufbauend spezielle Befragungen durchzuführen, die die Totalerhebung ersetzen werden.

Woher stammt die Zuverlässigkeit dieser sechs Daten, wenn doch der Rest "Schrott« sein soll? Ganz einfach. Ihrer Sicherstellung galten mehrere besondere Vorkehrungen:

- einmal der (zulässige) »umgekebrte Melderegisterabgletch : die Lieferung von Meldedaten an die Statistikämter bzw. Erhebungsstellen zur Erstellung der Zählerlisten. $\mathrm{Ob}$ diese Daten zutrafen, wurde durch die Zähler eigens evaluiert, d.h. überprüft und korrigiert, sogar in einem speziellen Erhebungsverfahren (\$S I0 Abs. 7; $1_{3}$ Abs. 5). Freilich nicht vollkommen: ganze Straßenzüge sind bekanntlich unerfaßt geblieben. Hier setzt die zweite Vorkehrung ein:

- die im Volkszählungsgesetz '87 vorgesehene und bisher zu wenig beachtete Möglichkeit der "Ersatzvornabme», d. h. der Ausfüllung der Zählungsbögen hinsichtlich der Grunddaten durch die Erhebungsstellen aufgrund der Meldedaten ( II Abs. I) auch ohne den Zähler. Reicht auch das nicht, so greift das neue Bundesstatistikgesetz 1987 ein.

- Es eröffnet den Statistikämtern (in $₫ \varsigma$ Abs. $\varsigma$ ) ein »besonderes Zugangsrecbt zu (öffentlichen) Registern «. Damit können die Grunddaten auch später laufend aktualisiert werden: durch die Daten der Register aus den Personalausweis-Antragsformularen, ebenso der maschinenlesbaren Pässe, der künftigen Arbeiter- und Krankenkarten (im jetzigen Gesetzesbündel 1988 zur Strukturreform des Gesundheitswesens "Sozialversicherungsausweis» und "Krankenversicherungskarte« genannt). Damit sind die Grundlagen für künftige statistische Arbeit der Statistikämter und empirischen Sozialforscher durch diese Volkszählung erst einmal gelegt. Was uns da bevorsteht, ist umfassend und total: Man kann es für den staatlichen Bereich nachlesen im gespenstischen Aufgabenkatalog des BStatG 1987.

(2) Der zweite, und, wie ich meine noch größere Erfolg ist die Durchsetzung der Blocksette. Bekanntlich stammt sie aus Polizeitaktik, genauer einer dreidimensionalen EDV-Fortentwicklung der Kriminalitätsstatistik durch den damaligen Polizeipräsident der Stadt Nürnberg, Horst Herold: Wenn man über statistische Daten über abweichendes Verhalten (Begehungsart) ein Zeitraster (Begehungszeit) und ein Ortsraster (Begehungsort) legt, dann schickt man die Funkstreifen dort hin, wo Ganoven statistisch wahrscheinlich einen Bruch machen wollen. Dieses kriminalpräventive und -repressive EDV-Instrument ist das Vorbild der Blockseite.

Der »kleinräumıge Bezugsrabmen «, wie er in den $70 e r$ Jahren deutlicher hieß, oder jetzt verharmlosend »kleinräumige Gliederung «, wurde theoretisch gefordert von den nationalsozialistischen Statistikern der $38 \mathrm{er}$ Jahre, um die Totalerfassung für Wehr- und "gesellschaftssanitäre $Z$ Zwecke zu effektivieren. Jetzt endlich ist er auch technisch machbar. Ihn durchzusetzen war nach meiner Überzeugung das zweite inhaltliche Hauptziel der Volkszäblung, neben den sechs Grunddaten.

Wofür braucht man die Blockseite? Sie bedeutet in Verbindung mit der übrigen Technisierung des Staates eine neue Qualität behördlicher Einwirkungsmöglichkeiten. Es erweitert sie nämlich in dreifacher Hinsicht:

- Für alle Behörden des Staates, nicht nur für Kriminalbeamte, sondern für den ganzen Staatsapparat, wird dieses ursprünglich kriminal-präventiv/repressive Instrument verallgemeinert;

- zudem für unbesttmmte Zwecke, d. h. für alle Zwecke dieser Behörden (auch für solche, die noch in Zukunft hinzukommen können). Also nicht nur zwecks Verbrechensverhinderung, sondern auch zur Gesundheitskostendämpfung oder polizeilichen Sicherung, gegen AIDS, zur Ausländerabgrenzung oder zur Ruhigstellung der Arbeitslosen; zur Kriminalisierung bestimmter Bevölkerungsgruppen 
(wenn man »schwarze Schafe« braucht) - oder auch für begrüßenswerte Maßnahmen. Denn es ist ein abstraktes Instrument, das erst mit Inhalten gefüllt werden muß.

- Nun brauchen Behörden nicht mehr nur personenbezogen vorgehen, sondern man kann jetzt zusätzlich gruppen- oder ortsbezogen, d. h. »kleinräumig", arbeiten, und zwar bundesweit oder straßeneng und mit beliebigen Merkmalskombinationen (das macht die Datenverarbeitung). In sozialwissenschaftlicher Sicht: Erstmals können Behörden nicht nur »soziale« Gruppen zum Objekt ihres Handelns machen, sondern auch in der Realität nicht aufeinander bezogene Personenmehrheiten, deren einzige Gemeinsamkeit auf der Datenebene besteht (z. B. walle russisch sprechenden Zwitter oder - etwas realistischer - alle AIDS-Verdächtigten, oder alle alleinstehenden Bewohnerinnen von Hochhäusern, die ihre Stromrechnung nicht selbst bezahlen) - eine Einladung zur Schleppnetz- oder Rasterfahndung durch nicht im voraus festliegende staatliche Stellen.

Ich bin nicht sicher, ob die Verwaltungen, abgesehen von technischen Eliten, bereits erkannt haben, welches gefährliche Werkzeug ihnen die Statistiker in die Hand gegeben haben. Aber Verwaltungskenntnisse neigen zur Verallgemeinerung - und zur Anwendung. Minderheiten können nun nicht nur repressiv, sondern auch präventiv in den Griff genommen werden. Rechtsstaatliche Sicherungen hierzu gibt es bisher nicht, da der Rechtsschutz überwiegend individualistisch ausgelegt ist. Nur verkehrt sich ein bisheriges Grundprinzip westlicher Demokratie, nämlich der Minderheitenschutz, ins tendenzielle Gegenteil. Gleichwohl hat das Bundesverfassungsgericht kürzlich in einer unveröffentlichten (Volkszählungs-)Entscheidung zwar das politische Problem der Blockseite erkannt, es aber als verfassungsrechtlich unproblematisch abgetan (dazu unten).

Zur Erläuterung: Die Volkszählung beginnt mit der Weitergabe eines Grundstamms an Personaldaten aus dem Melderegister an die Statistikämter (der umgekehrte Weg ist durch das Volkszählungsurteil ' 83 verwehrt); dort wird das Zeitraster darüber gelegt (= Stichtag der Volkszählung, oder, soweit das gescheitert ist, durch die Stichtage auf den Antragsformularen für die oben genannten vier maschinenlesbaren Ausweise und Karten, weil diese eine eindeutige zeitliche Identifizierung dieser Personen erlauben); das zusätzlich erforderliche Ortsraster erbringt wieder die Volkszählung durch Auswertung der korrigierten Zählerlisten, und wo diese versagen, der aufgeführten Formulare bzw. der daraus resultierenden Dateien und Register.

Diese dreidimensionale EDV-Kartographierung aller Personen und Gruppen der Gesamtbevölkerung und ibre computergesteuerte Programmierung für fast beliebige Zwecke ist das grundlegend Neue dieser Volkszählung 1987 - als unentbehrlicher Bestandteil der fortschreitenden Maschinisierung der Gesellschaft.

\section{Die derzentzge juristische Posttion des Bundesverfassungsgerichts}

Wie steht das BVerfG unter der neuen Ägide dazu? Widersprüchlich, analysiert man die letzten Abweisungen von Verfassungsbeschwerden aus dieser Volkszählung (herangezogen wurden vor allem die unveröffentlichten Entscheidungen mit den Aktenzeichen I BvR 620, 970, 1063, 1 I 22/87). Folgende Tendenzen sind feststellbar:

(I) Das BVerfG argumentiert jetzt stärker individualistisch. Es sagt sinngemäß: Wir werden dort einzelnen Personen zu Hilfe kommen, wo diese, subjektiv glaubhaft, individuelle Verletzungen ihrer Grundrechte darlegen können, und wo sie nicht vermutlich anderwärts publizierte Begründungen abgeschrieben haben; aber im 
jeweils vorliegenden Fall sei das nicht gegeben. - Dies erscheint als einseitige Subjektivierung gegenüber dem auch konstruktiv-organisatorischen Gestaltungsansatz, wie er noch im Volkszählungsurteil ' 83 enthalten war.

(2) Im übrigen werden bisher alle Verfassungsbeschwerden abgewiesen und die Abweisungen mit einer sehr scharfen Funktionsteilung zwischen Verfassungsgericht und Verfassung einerseits, Fachgerichten (also Verwaltungsgerichten) und parlamentarischen Gesetzen andererseits begründet. Zum Ausgleich werden den Fachgerichten hohe Aufklärungs- und Sorgfaltspflichten auferlegt (denen diese aber bisher meist nicht nachkommen), da der Bürger nicht die Interna der Verwaltungsautomation kennen könne. Dagegen seien Verletzungen des Volkszählungsgesetzes bei der Anwendung des Gesetzes, und seien sie auch noch so grob, bloße Verstöße gegen dieses Gesetz, noch lange nicht Verstöße dieses Gesetzes gegen die Verfassung.

(3) Eine (juristisch nur scheinbare) Ausnahme will man machen: Offensichtlich möchte man noch im technischen Bereich einige Lücken der alten Volkszählungsentscheidung schließen. Dazu fehlen noch Verfassungsbeschwerden. Sie werden sogar direkt herausgefordert. Im übrigen aber wolle man jetzt nur noch ganz grundlegende Fragen zur Entscheidung annehmen. - Das heißt also, Mutige sollen zusammen mit Experten klagen; die Bürger im übrigen haben wenig Chancen.

Tatsächlich wurde bisher in keiner Entscheidung geprüft oder auch nur angedacht, ob die Abschottung der Rechenzentren der Erhebungsstellen genüge. Die Erhebungsstellen selbst sind von den Ländern im wesentlichen abgedichtet worden, wenigstens auf der normativen Ebene der Verordnungen. Da aber die Erhebungsstellen überwiegend nur die Fragebogensammelstellen sind, gehen die Bögen meist sofort ins Rechenzentrum. Die Rechenzentren sind bundesweit nicht in die korrekte organisatorische Abschottung durch die Rechtsverordnungen einbezogen worden (auch in Hessen nicht). Das liegt an der einseitig juristischen Ausrichtung der beigezogenen Datenschutzbeauftragten. Hier ist noch eine gewisse Chance für Informatiker in Zusammenarbeit mit Verfassungsjuristen. Aber das ist nur eine geringe Chance, und nur in einem Bereich; sie führt auch nur zu einer technischen Optimierung des alten Volkszählungsurteils.

Ferner ist bisher noch keine Entscheidung über Buß-oder Zwangsgelder ergangen. (4) Im übrigen zeigt man sich auf der Höhe der fachlichen Boykott-Argumentation; freilich nicht zugunsten der Bürgerinnen. So hat das Verfassungsgericht durchaus erkannt, was von der Boykottbewegung als verfassungswidrig moniert wurde, daß dieses Volkszählungsgesetz ' 87 entgegen den ursprünglichen Anforderungen des Volkszählungsurteils ' 83 keine "faktisch anonymisterten" statisttschen Daten mehr verlangt. Das wird aber nun in den Grenzen der Praxis als sozialadäquat und unvermeidlich zugestanden und als verfassungsmäßig anerkannt - in Aufweichung der klaren Linie des ersten Volkszählungsurteils. Das BVerfG steht hierzu auf dem unrealistischen Standpunkt, es genüge, einen geschlossenen Datenkreislauf zwischen den statistischen Bundesämtern, statistischen Landesämtern und statistischen Kommunalämtern zu installieren. So läuft die Datenverarbeitung in der Praxis der staatlichen Rechenzentren und der Verwaltungsorganisation mitnichten.

Übrigens wurde die Pseudoanhörung handverlesener Statistikfachleute vor dem Innenausschuß des Bundestags vom BverfG als Erfüllung seiner Forderung anerkannt, wonach vor dem Volkszählungsgesetz '87 die Wissenschaft zur Frage der Erübrigung künftiger Totalerhebungen durch schonendere Verfahren Stellung zu nehmen habe - auch eine Niederlage.

(5) Was das Schlimmste ist: Man verkennt das undemokratische, weil minderheitengefährdende Risikopotential der Blocksette. Das höchste deutsche Gericht vertritt konsequenten Individualismus: In der Entscheidung 1 BvR 1063/87 wird auf's 
deutlichste gesagt, es sei verfassungsrechtlich unbedenklich, wenn künftig beliebige Behörden individuelle Datensätze aus der Volkszählung, wenn sie nur »anonymisiert « sind, mit Blockseite für beliebige Verwaltungszwecke gegen einzelne Gruppen der Bevölkerung einsetzen, vorausgesetzt nur, daß keine individuellen Grundrechtsverletzungen namhaft gemacht werden können, d.h. technisch: daß die Blockseiten etwas zusammengefaßt werden (VZG '87 \$ Is Abs. 4 Satz 4 ):

»Der ... Einwand des Beschwerdeführers, die ... Weitergabe kleınräumig gegliederter statistischer Ergebnisse könne... der Verwaltung Hinweise auf gezielte Verwaltungsvollzugsmaßnahmen geben, rechtfertigt kein Eingreifen des Bundesverfassungsgerichts. Werden (solche) Daten zum Anlaß genommen, Verwaltungsvollzugsmaßnahmen etwa durch gezielte Betrachtung bestimmter Personengruppen oder Gebiete, etwa bestımmter Blocksetten (Hervorhebung W. St.) vorzuberetten, widerspricht dies (nicht der Verfassung), wenn und soweit kleinraumbezogene Spezialaufbereitungen nıcht die Grenze der Deanonymisierbarkeit überschreiten«.

Das ist aber völlig unrealistisch, und kann zudem im Einzelfall nicht mehr nachgeprüft werden: Jede Fachbehörde verfügt aus ihren Akten und Datenbanken normalerweise über das zur Repersonalisierung erforderliche Zusatzwissen.

(6) Allerdings verlangt das BVerfG nun, und auch das ist neu - und begrüßenswert -, daß massive technische und organisatorische Datensicherungsmaßnabmen im Dienste des Datenschutzes zur Abschottung dieses geschlossenen Kreislaufs getroffen werden. Da das Gericht sich aber bisher weigert, die Einhaltung dieser korrekten Anforderung auch von sich aus nachzuprüfen - der Bürger ist dazu so wenig imstande wie der vor verschlossenen Türen stehende Experte oder Verwaltungsgerichte -, bleibt diese Vorgabe auf dem Papier.

Man kann also zusammenfassen: Die individualistische Wende des BVerfG läßt nur noch wenige Ansatzpunkte für ein erfolgversprechendes Vorgehen gegen das VZG '87. Lediglich die fehlende technische Abschottung der Rechenzentren bei der Datenerfassung im Rahmen der Erhebungsstellen verspricht nach gründlicher empirischer und informatischer Vorbereitung noch eine gewisse - palliative - Chance. Im übrigen ist die Totalerhebung als solche gescheitert. Doch sie wird wegen der insoweit geglückten Erhebung der Grunddaten für andere Formen der Bevölkerungsvermessung auch nicht mehr benötigt. All das verschlägt wenig gegenüber dem "Fortschritt «, den die Zählung en passant für die weitere innere Aufrüstung des Staatsapparats gebracht hat: die Durchsetzung der EDV-Blockseite als des informationstechnischen Blockwarts der Datenzeit. 